Article

\title{
Experimental Investigation on Injection and Production Pattern in Fractured-Vuggy Carbonate Reservoirs
}

\author{
Juan $\mathrm{He}^{1,2,3,4}$, Aowei $\mathrm{Li}^{4, \dagger}$, Shanshan $\mathrm{Wu}^{4, \dagger}$, Ruixue Tang ${ }^{4, *}$, Dongliang $\mathrm{Lv}^{4}$, Yongren $\mathrm{Li}^{4}$ \\ and Xiaobo $\mathrm{Li}^{5}$ \\ 1 Key Laboratory of Renewable Energy and Gas Hydrate, Guangzhou Institute of Energy Conversion, CAS, \\ Guangzhou 510640, China; hejuan@ms.giec.ac.cn \\ 2 Guangdong Provincial Key Laboratory of New and Renewable Energy Research and Development, \\ Guangzhou 510640, China \\ 3 University of Chinese Academy of Sciences, Beijing 100049, China \\ 4 State Key Laboratory of Oil and Gas Reservoir Geology and Exploitation, Southwest Petroleum University, \\ Chengdu 610500, China; lawhhd@163.com (A.L.); hermione533wss@163.com (S.W.); \\ Lvdongliang@swpu.edu.cn (D.L.); liyongren123@163.com (Y.L.) \\ 5 Research Institute of Petroleum Engineering and Technology, Northwest Oilfield Company, Sinopec, \\ Urumqi 830011, China; Lxb969@163.com \\ * Correspondence: ruixue.tang1@ucalgary.ca \\ + The author contributed equally to this work and should be considered co-first authors.
}

Received: 11 December 2019; Accepted: 21 January 2020; Published: 29 January 2020

\begin{abstract}
To constitute and adjust the injection and production pattern in fractured-vuggy reservoirs, we extracted twelve fractured-cave structures, fabricated them into physical models with acrylic plates, and performed experiments via these models. The results show that utilizing oil/water gravity segregation sufficiently and forming valid flow channels should be emphasized. Preferentially exploiting the reservoir body containing intermediate-scaled or large-scaled caves, arranging injection wells in fractures or small-scaled caves while placing production wells in large-scaled caves, and separately putting injection wells and production wells in low/high parts of an intermediate-scaled or large-scaled cave, were found to benefit oil/water gravity segregation and thus gain a better water flooding effect in these experiments. Experiments with combined models also figured out that, after adjusting the injection and production pattern, the valid flow channel newly formed must pass through caves containing enough residual oil to improve the water flooding effect and could be obtained by shutting down the old production well while adding a new production well, adding a new production well, or switching the production well into an injection well while adding a new production well. In the actual field, adjusting the well location and altering the flow channel were proposed to conduct together. This study may provide references on the production management of analogous reservoirs.
\end{abstract}

Keywords: fractured-vuggy reservoirs; physical model; water flooding effect; injection and production pattern; gravity differentiation; flow channel

\section{Introduction}

Carbonate reservoirs take almost 60 percent of global hydrocarbon resources, so it is crucial to the world's energy supply. In China, this proportion exceeds $25 \%$. The Ordovician reservoir of the Tahe oilfield, Tarim Basin, is the largest fractured-vuggy carbonate reservoir in China. Since the matrix of the carbonate rock cannot store oil and has extremely low permeability $[1,2]$, caves and fractures are 
reckoned as the main storage spaces, easily causing severe mud loss in drilling like other karst formations in the world [3]. Meanwhile, undergoing tectonic movements and karst processes, these caves and fractures possess various types, scales, and distributions. Therefore, unlike porous and fractured-porous carbonate reservoirs in China, the distinguishing features of the Tahe oilfield suffer from severe heterogeneity, complex space structure, and intricate flow mechanisms [4-6]. These traits cause the difficulty of constituting injection and production patterns in this reservoir. In clastic reservoirs, the well pattern is to enlarge sweep areas, so the water flooding effect can be improved by adjusting the injection layers directly. Nevertheless, using the same method is invalid for the injection and production pattern in this reservoir because of the random distributions and the poor connectivity of storage spaces [7].

Recently, various physical fractured-vuggy models were utilized to investigate the mechanism of water or gas displacement. In some of these models, practical irregular caves were simplified into circles [8-10], spheres [11], or cylinders [12], while original space structures of caves were preserved in other models [13-22]. Although the latter did display the remaining oil distributions much better, their well placements were predetermined in most of these experiments. Both Zhang [23] and Wang et al. [24] verified that a nine-spot well network behaved better in performances of water drive in fractured-vuggy reservoirs by using specific distributions of fractures and caves. However, this conventional well network is difficult to use in fractures and caves with variable spatial distributions. In fact, the phrase 'well net' is not suitable in fractured-vuggy reservoirs because the well placement is governed by reservoir bodies instead of layers. From the practice perspective, $\mathrm{Li}$ and Rong [25] proposed that well placement should be considered from the connectivity of wells, the reservoir body type, the position for production and injection, and the fluid distribution. Lu et al. [26] further developed the injection/production well pattern based on reservoir spatial structures, but there are currently few practical effects to support this idea. In addition, because of extreme heterogeneity weakening the function of the Darcy law $[27,28]$, the present numerical simulations about the well pattern design in traditional oil and gas reservoirs [29-38] cannot solve problems effectively in this reservoir. With the lasting exploitation, the exposed disadvantages in the original injection and production pattern are harming the production in this oilfield. However, there are presently few systematic understandings and sustainably valid measures on the injection and production pattern to face up with these problems. Hence, it is urgent to perform relevant surveys.

In this work, physical simulation was employed to explore how to build and adjust the injection and production patterns in fractured-vuggy reservoirs. On the basis of designed and fabricated physical models, experimental schemes were designed and carried out from reservoir body types, injection/production relationships, high/low positions of a reservoir body, and injection and production adjustments, respectively. Through comparing the water flooding effect in four aspects, we analyzed some key points and achieved corresponding adjusting measures on the injection and production patterns in fractured-vuggy reservoirs.

\section{Experiment}

\subsection{Model Design and Fabrication}

According to the cognition about the spatial distribution, the geometrical morphology, and the connectivity in reservoir bodies [31,39-44], twelve typical fractured-cave structures were extracted from Block S74 in the Tahe oilfield (Figure 1a). The simplification of a geological explanation was presented in previous work [45]. These structures were divided into the large scale, the intermediate scale, and the small scale. In actual reservoirs, their sizes ranged from 34.5-39, 16.5-24, and 0.6-6 m, respectively. These fractured-cave structures were further fabricated into $3 \mathrm{D}$ physical models with a proportion of 300:1 (Figure 1b). 


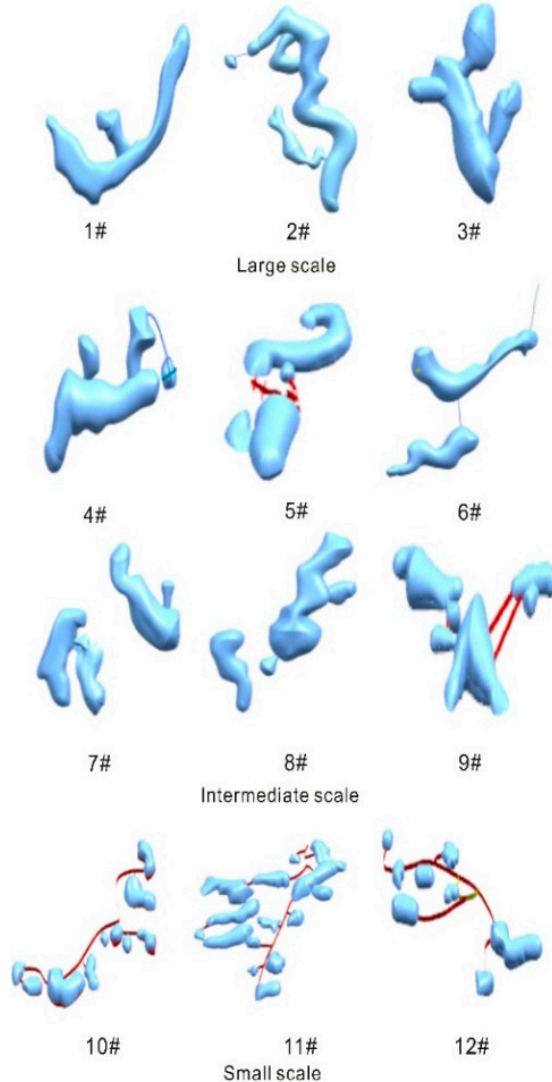

(a) 3D reservoir bodies
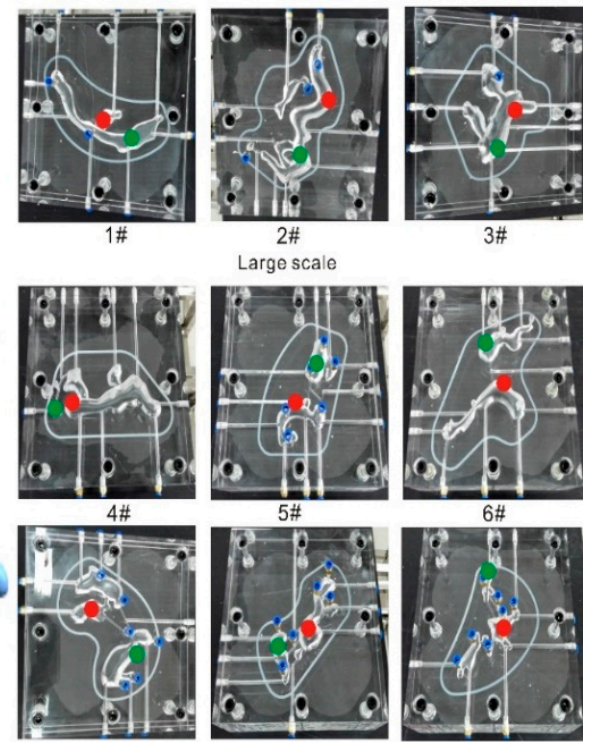

$7 \#$
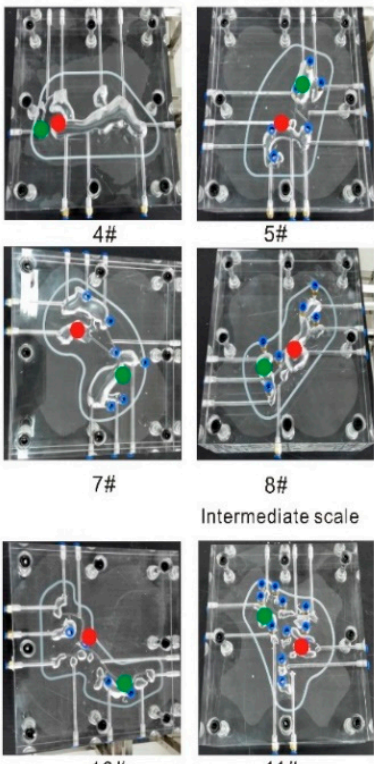

$10 \#$

(b) Physical models
$8 \#$

Intermediate scale

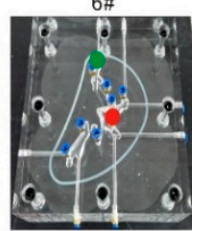

9\#

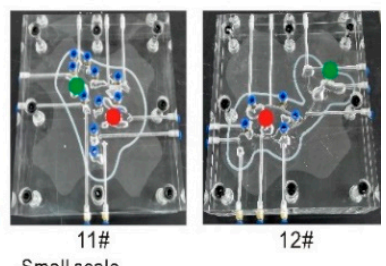

Figure 1. The typical fractured-cave structures (a) and the physical models (b). Red filled sources represent production wells. Green filled sources are injection wells.

A single model was composed of two weak oil-wet acrylic plates with a scale of $300 \times 300 \times 50 \mathrm{~mm}$ (length $\times$ width $\times$ height). After the morphology of fractures and caves was engraved in two plates, a packing ring around the caves and fractures was fixed in a groove to avoid fluid leakage (Figure 2). Inlets and outlets were drilled on the surface of a plate with holes with a diameter of $6 \mathrm{~mm}$. Their locations resembled actual well placements. Finally, two plates were combined together with eight screw bolts as a body.

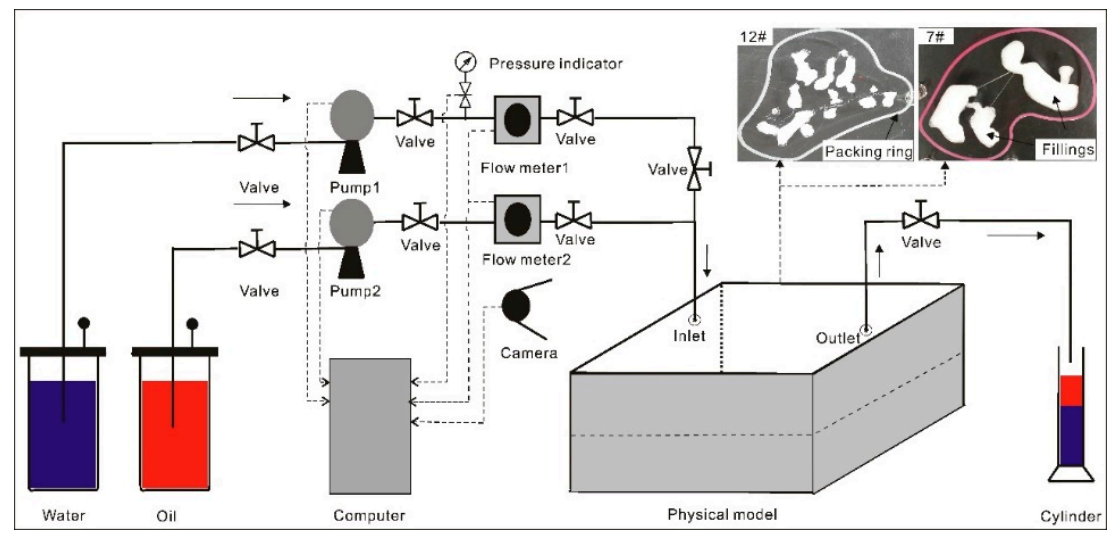

Figure 2. Experimental apparatus.

In these physical models, the size ranges of vugs are $115-130,55-80$, and $2-20 \mathrm{~mm}$, respectively. Fractures were controlled with a width of $0.5-2 \mathrm{~mm}$ and crack density of $1-5 \mathrm{~m}^{-1}$. The matrix was treated as an ineffective reservoir [1,2], so it was ignored in these physical models. 


\subsection{Experimental Materials and Setups}

Figure 2 shows the main devices.

Two containers of about 1.2 L of artificial store water and white oil, respectively. The artificial water with a density of $1200 \mathrm{~kg} / \mathrm{m}^{3}$ simulated the underground water. The white oil with a density of $855 \mathrm{~kg} / \mathrm{m}^{3}$ and a dynamic viscosity of $26 \mathrm{mPa} \cdot \mathrm{s}$ substituted for the crude oil. The pump (BT100LG) with the power of $22 \mathrm{~W}$ supplied the drive to inject artificial water or white oil into the physical model, and its flow rate ranged from $0.0015 \mathrm{~mL} / \mathrm{min}$ to $380 \mathrm{~mL} / \mathrm{min}$. The fluid volume from the pump was measured and corrected by a flow meter (LZB-3WB) in which the range of flow rate varied from 4 to $40 \mathrm{~mL} / \mathrm{min}$. Two pumps and two flow meters were prepared to avoid ongoing experiment interruptions from device failures. A pressure gauge (0-500 KPa) with an accuracy of $0.5 \%$ measured pressure changes of the corresponding pump.

In the single model, the void consists of fractures and caves. Its bulk ranged from 78.1 to $331.9 \mathrm{~mL}$. Before injecting white oil into the void, the filling was replaced by 10-20 mesh quartz sand with about half of the void bulk. At the same time, a balance (ZH-20H7) of max-capacity of $20 \mathrm{Kg}$ and an accuracy of $0.2 \mathrm{~g}$ measured the mass changes of the model. A cylinder with $500 \mathrm{~mL}$ reserved displaced fluid from the model during water flooding and metered its volume. Four cameras (JVS-N73-G1 $3.6 \mathrm{~mm}$ ) videoed the whole experimental process. A computer recorded all relevant data.

\subsection{Experimental Design}

The whole investigation was divided into constituting the injection and production pattern (Table 1) and the adjusting injection and production pattern (Table 2).

Table 1. The experimental contents for well placement design.

\begin{tabular}{cccc}
\hline Type & Subtype & Models & Amounts \\
\hline \multirow{3}{*}{ Types of reservoir bodies } & Large scale & $1 \#-3 \#$ & 3 \\
& Intermediate scale & $4 \#-9 \#$ & 6 \\
& Small scale & $10 \#-12 \#$ & 3 \\
\hline \multirow{3}{*}{ Injection/production relationships } & FIIVO vs. FOIVI & $4 \#, 7 \#, 8 \#$ & 6 \\
& FISVO vs. FOSVI & $10 \#-12 \#$ & 6 \\
& SVIIIV vs. SVOLIVI & $2 \#, 4 \#, 9 \#$ & 6 \\
\hline \multirow{3}{*}{ High/low position of the reservoir body } & HIHO & $2 \#, 6 \#, 11 \#$ & 3 \\
& LIHO & $2 \#, 6 \#, 11 \#$ & 3 \\
& HILO & $2 \#, 6 \#, 11 \#$ & 3 \\
& LILO & $2 \#, 6 \#, 11 \#$ & 3 \\
\hline
\end{tabular}

Note: Fractures (inlets) and intermediate-scaled vugs (outlets) vs. fractures (outlets) and intermediate-scaled vugs (inlets) are abbreviated as FIIVO vs. FOIVI. Fractures (inlets) and small-scaled vugs (outlets) vs. fractures (outlets) and small-scaled vugs (inlets) are simplified into FISVO vs. FOSVI. Small-scaled vugs (inlets) and large-scaled or intermediate-scaled vugs (outlets) vs. small-scaled vugs (outlets) and large-scaled or intermediate-scaled vugs (inlets) are abridged into SVIIIV vs. SVOLIVI.

The contents in Table 1 were designed from types of reservoir bodies, injection/production relationships, and high/low positions of the reservoir body.

The sizes of caves and the connectivity properties are the main contributors of reservoir bodies. In various storage spaces, larger caves may store more oil. In Figure 3, since the sizes of caves in Models 2\# and 7\# are larger than those in Model 12\#, by placing the wells in caves of these two models, it is possible to gain higher outputs. On the other hand, the means of the connectivity among caves encompasses the dissolved caves (yellow rectangles in Figure 3) and fractures (yellow circles in Figure 3). Theoretically, the flow resistance is smaller in the dissolved caves, so it is much easier to flow in them. This may further affect the development effect for different reservoir bodies. Therefore, for reservoir bodies, the sizes and connectivity properties determine which type should be selected preferentially to develop. Both factors were also used to classify these models into three types (Table 1). 
Under the fixed injection and production pattern (Figure 1b), the valuable reservoir bodies would be chosen by the comparison of the water flooding effect.

Table 2. The experimental schemes of well placement adjustments.

\begin{tabular}{|c|c|c|c|c|c|c|}
\hline \multirow{2}{*}{$\begin{array}{l}\text { Adjusting } \\
\text { Measures }\end{array}$} & \multirow{2}{*}{$\begin{array}{l}\text { Combined } \\
\text { Models }\end{array}$} & \multicolumn{2}{|c|}{ Before $3.0 \mathrm{PV}$} & \multicolumn{2}{|c|}{ After 3.0 PV } & \multirow{2}{*}{ Note } \\
\hline & & Injection Well & Production Well & Injection Well & Production Well & \\
\hline \multirow{2}{*}{ Scheme 1} & (7)(3) & S74 & TK629 & TK629 & S74 & 1 \\
\hline & (7)(8) & S74 & TK651CH & TK651CH & S74 & 1 \\
\hline \multirow{3}{*}{ Scheme 2} & (6)(4) & TK617CH & TK608 & TK617CH & TK608 & $\begin{array}{l}\text { Increasing amounts of } \\
\text { connected channels from } \\
\text { one to two }\end{array}$ \\
\hline & (7)(11) & S74 & TK652 & S74 & TK652 & $\begin{array}{l}\text { Increasing amounts of } \\
\text { connected channels from } \\
\text { one to three }\end{array}$ \\
\hline & (11)(4) & TK652 & TK608 & TK652 & TK608 & $\begin{array}{l}\text { Increasing amounts of } \\
\text { connected channels from } \\
\text { one to three }\end{array}$ \\
\hline \multirow{3}{*}{ Scheme 3} & (3)(4) & TK629 & TK608 & TK629 & $x$ & Shutting down TK608 \\
\hline & (6)(7) & TK617CH & TK612 & TK617CH & TK6104X & Shutting down TK612 \\
\hline & (6)(11) & TK617CH & TK605CH & TK617CH & Z & Shutting down TK605CH \\
\hline \multirow{3}{*}{ Scheme 4} & (3)(7) & TK629 & TK612 & TK629 & TK612/Z & 1 \\
\hline & $8(8)$ & TK651CH & TK612 & TK651CH & TK612/S74 & 1 \\
\hline & (8)(10) & TK651CH & TK659 & TK651CH & TK659/A & 1 \\
\hline \multirow{3}{*}{ Scheme 5} & (7)(11) & $\mathrm{S} 74$ & TK605CH & $\mathrm{S} 74$ & TK605CH/TK6104X & 1 \\
\hline & (11)(7) & TK651CH & TK605CH & TK651CH/B & TK605CH & 1 \\
\hline & (8)(11) & TK652 & TK612 & TK652/TK6104X & TK612 & 1 \\
\hline \multirow{3}{*}{ Scheme 6} & (6)(3) & TK629 & TK617CH & TK629/TK617CH & TK617 & 1 \\
\hline & (10)(7) & TK659 & TK612 & TK659/TK612 & Z & / \\
\hline & (11)(3) & TK652 & TK629 & TK652/TK629 & C & I \\
\hline
\end{tabular}

Note: Scheme 1 stands for the measure of exchanging locations of the production well and injection well. Scheme 2 means the measure of adding numbers of connected channels. Scheme 3 refers to the measure of closing the old production well while opening the new production well. Scheme 4 represents the measure of opening the old production well while opening the new production well. Scheme 5 is the measure of adding the injection well. Scheme 6 is defined as the measure of switching the old production well into the new injection well while adding the production well.
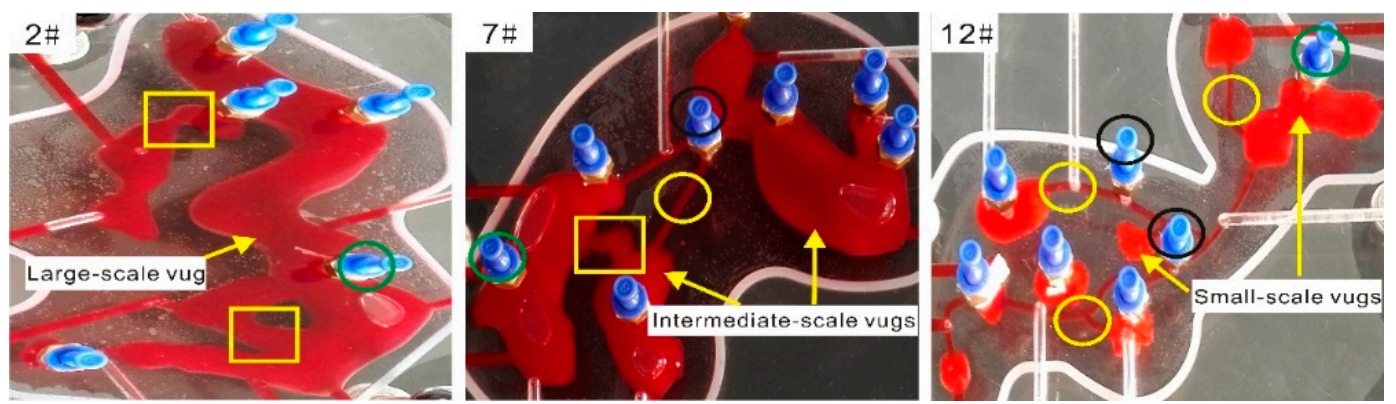

Figure 3. The connectivity features in three kinds of reservoir bodies.

The injection/production relationships describe how to arrange wells in selected reservoir bodies to achieve a better water flooding effect. Since either the injection well or production well may be located in the caves (green circles in Figure 3) or fractures (black circles in Figure 3), there are three pairs of injection/production relationships (Table 1). Their well placements are presented in Figure 4. The suitable well placements will be gained through evaluating water flooding. 


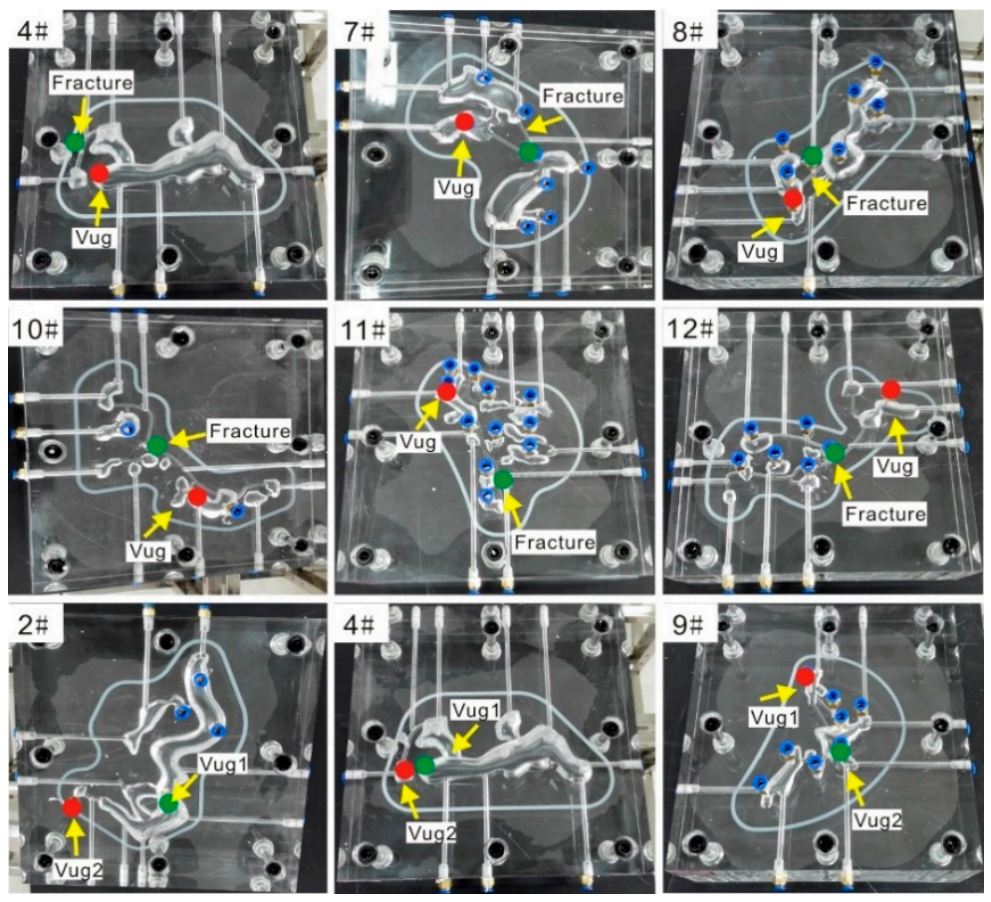

Figure 4. The well locations of FIIVO, FISVO, and SVIIIV. Exchanging orders of red and green filled sources corresponds to FOIVI, FOSVI, and SVOLIVI in the same models.

The high/low position of a reservoir body has impacts on the water flooding effect. Possible well placements include four combinations (Table 1) in which the corresponding locations in the vertical direction are shown in Figure 5a-d, respectively. In every model, the best injection and production pattern was attained by comparing the water flooding effect in four combinations.

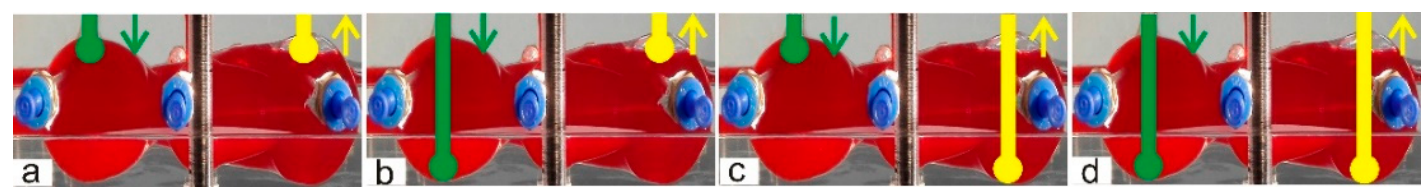

Figure 5. The schematic diagrams of (a) HIHO, (b) LIHO, (c) HILO, and (d) LILO.

In Table 2, the combined models were used to investigate the effect of different adjusting measures (Schemes 1-6), respectively. The combined models were composed of two single models. The theory of combination is as follows. Firstly, the connectivity between two wells was judged with dynamic tracer monitoring. Secondly, if two wells were supposed to connect to each other, the corresponding two physical models were combined together. Thirdly, the styles and amounts of connected channels resembled actual connected channels, including large fractures, fractures, and three parallel fractures in Block S74. In these experiments, large fractures and fractures were replaced by a single plastic pipeline with diameters of 6 and $3 \mathrm{~mm}$, respectively. Three parallel fractures were simulated with three plastic pipelines with the same diameter of $3 \mathrm{~mm}$. The above specific messages were presented in our published work [45].

HIHO refers to the high position (inlet) and high position (outlet). LIHO is the low position (inlet) and high position (outlet). HILO represents the high position (inlet) and low position (outlet). LILO means the low position (inlet) and low position (outlet). 


\subsection{Experimental Procedure}

The following contexts are the main procedures of experiments. On the basis of these steps, the injection and production pattern was adjusted after 3.0 PV, and then water injection was stopped at 5.0 PV. The other steps are similar in two kinds of experiments.

At first, some preparations were required. (1) The artificial water was colored with methyl blue, and the white oil was dyed with oil soluble. (2) The mass of quartz sand is the difference value of the mass between the model containing fillings and the model without fillings. (3) The model with fillings was saturated sufficiently with the simulated oil, and then it was weighted. The mass of white oil is equal to the difference value of the mass between the model encompassing oil and the model without oil. (4) Operation (3) was repeated three times to reduce the disturbance of air on the measurement of the saturated oil mass. The main parameters of the quartz sand and the simulated oil are listed in Table 3.

Table 3. Basic parameters of the fillings and the saturated oil.

\begin{tabular}{|c|c|c|c|c|c|c|c|c|c|c|}
\hline \multirow[b]{2}{*}{ Number } & \multicolumn{3}{|c|}{ Mass of the Fillings/g } & \multicolumn{5}{|c|}{ Mass of the Saturated Oil/g } & \multirow[b]{2}{*}{$\begin{array}{l}\text { Simulated Oil } \\
\text { Volume/mL }\end{array}$} & \multirow[b]{2}{*}{$\begin{array}{c}\text { Pore } \\
\text { Volume/mL }\end{array}$} \\
\hline & $\begin{array}{c}\text { Model } \\
\text { without } \\
\text { Fillings }\end{array}$ & $\begin{array}{c}\text { Model } \\
\text { with } \\
\text { Fillings }\end{array}$ & Difference & Run 1 & Run 2 & Run 3 & Average & Difference & & \\
\hline $1 \#$ & $10,482.6$ & $10,537.6$ & 55.0 & $10,611.5$ & $10,609.9$ & $10,609.8$ & $10,610.4$ & 72.8 & 85.1 & 105.9 \\
\hline $2 \#$ & $10,787.8$ & $10,951.6$ & 163.8 & $11,135.3$ & $11,135.9$ & $11,135.6$ & $11,135.6$ & 184.0 & 215.2 & 277.0 \\
\hline $3 \#$ & $10,274.2$ & $10,530.4$ & 256.2 & $10,681.20$ & $10,682.1$ & $10,682.1$ & $10,681.8$ & 151.4 & 177.1 & 273.8 \\
\hline $6 \#$ & 11,164 & $11,250.6$ & 86.6 & $11,358.40$ & $11,359.7$ & $11,359.5$ & $11,359.2$ & 108.6 & 127.0 & 159.7 \\
\hline $7 \#$ & $10,615.6$ & $10,685.8$ & 70.2 & $10,804.20$ & $10,805.9$ & $10,805.5$ & $10,805.2$ & 119.4 & 139.6 & 166.1 \\
\hline $8 \#$ & $10,699.4$ & $10,792.2$ & 92.8 & $10,900.80$ & $10,903.2$ & $10,904.4$ & $10,902.8$ & 110.6 & 129.4 & 164.4 \\
\hline $9 \#$ & $10,824.6$ & $10,914.4$ & 89.8 & $10,965.30$ & $10,966.8$ & $10,964.7$ & $10,965.6$ & 51.2 & 59.9 & 93.8 \\
\hline $10 \#$ & 10,530 & $10,564.6$ & 34.6 & $10,619.90$ & $10,621.4$ & $10,619.3$ & $10,620.2$ & 55.6 & 65.0 & 78.1 \\
\hline $11 \#$ & $10,493.6$ & $10,642.0$ & 148.4 & $10,683.70$ & $10,686.2$ & $10,682.7$ & $10,684.2$ & 42.2 & 49.4 & 105.4 \\
\hline
\end{tabular}

We further carried out the experiments via maintaining the constant flow rate of $20 \mathrm{~mL} / \mathrm{min}$ and the total injection volume of 3.0 PV. The volume of the measuring cylinder was recorded with an interval of $0.5 \mathrm{PV}$. Meanwhile, the experimental phenomena were recorded by video.

In addition, the following details in the experiments should be emphasized. Firstly, the mass of the fillings was maintained approximately the same in the identical model. Secondly, exchanging the orders of the inlet and the outlet (Figure 4) was to ensure the unchanged flow path during water flooding. Thirdly, the use of a short pipeline with a diameter of $3 \mathrm{~mm}$ was used to model the low position of the reservoir body.

Finally, the water displacement efficiency and the water cut were calculated with Equations (1) and (2), separately.

$$
E D=\frac{V_{o}}{V_{\text {total }}} \times 100 \%
$$

$E D$ represents the water displacement efficiency, \%. $V_{o}$ stands for the output of oil, ml. $V_{\text {total }}$ means the total saturated oil volume, $\mathrm{mL}$.

$$
f_{w}=\frac{V_{w i}-V_{w j}}{V_{t i}-V_{t j}} \times 100 \%
$$

$V_{w i}$ and $V_{w j}$ are the output of the water at different data logging times $(i=j+1, j=0,1,2,3$, and 4), mL. $V_{t i}$ and $V_{t j}$ represent the corresponding total output of the water and the oil, $\mathrm{mL}$. 


\section{Results and Discussion}

\subsection{Constituting Injection and Production Pattern}

\subsubsection{Reservoir Body Types}

Figure 6 reveals the relationships between the water displacement efficiency, the water cut, and the injection volume.
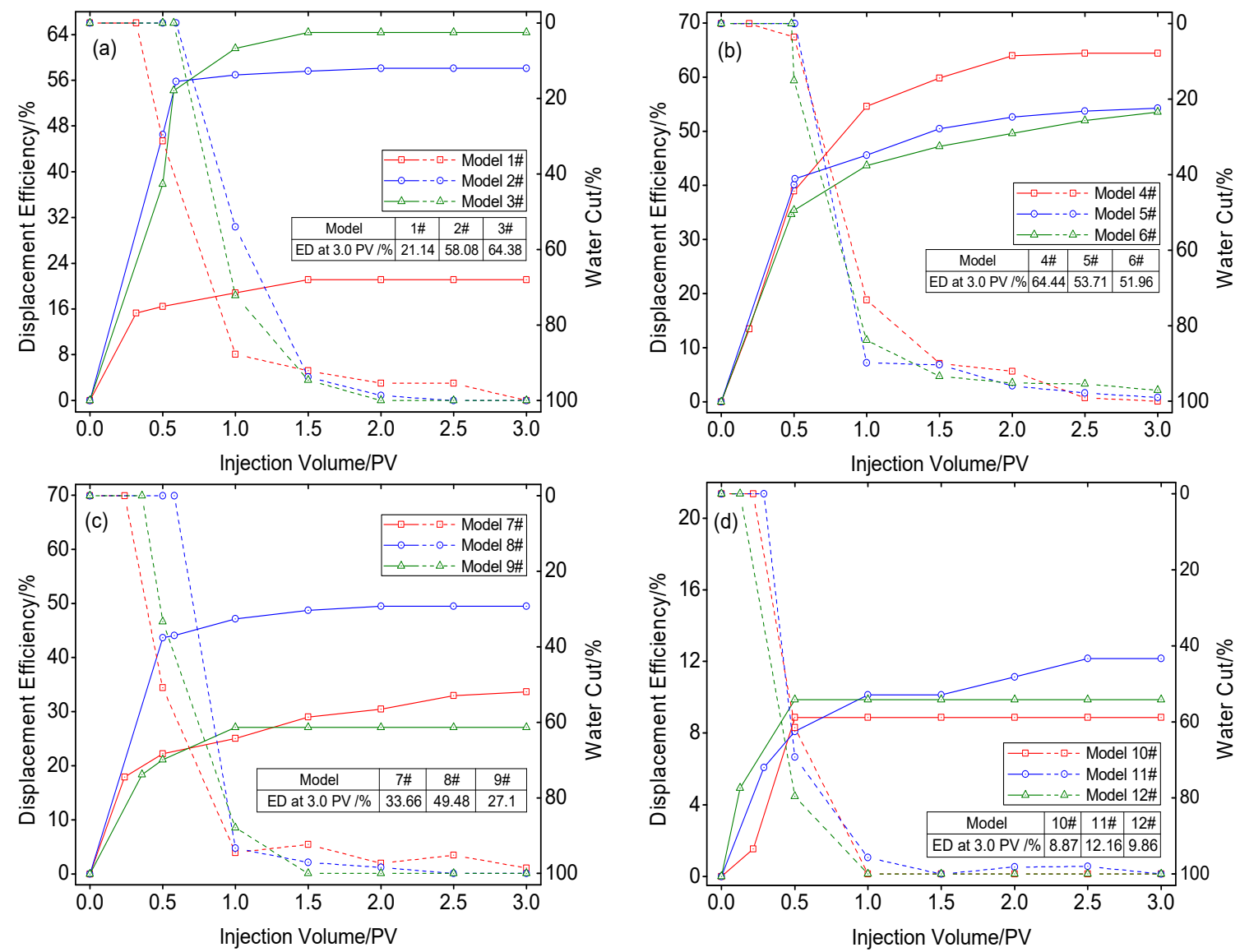

Figure 6. Displacement efficiency (solid lines) and water cut (dash lines) changes of reservoir bodies with large scales $(\mathbf{a})$, intermediate scales $(\mathbf{b}, \mathbf{c})$, and small scales $(\mathbf{d})$, respectively.

For large scale reservoir bodies (Figure 6a), the averaged final efficiency is $47.87 \%$, and the averaged time of their water-free oil production is $0.49 \mathrm{PV}$. The water cut arrived at $100 \%$ after $2.0 \mathrm{PV}$ in them.

For intermediate scale reservoir bodies (Figure $6 b, c)$, the averaged displacement efficiency of $47.08 \%$ at 3.0 PV approached this in the large scale reservoir bodies, but their averaged water breakthrough time was 0.1 PV earlier than the large scale reservoir bodies. The oil still was flushed out at 3.0 PV in Models 5\#-7\#. Their corresponding water cuts are 98.97\% (Figure 6b), 97.08\% (Figure 6b), and $98.61 \%$ (Figure $6 \mathrm{c}$ ), respectively.

For small scale reservoir bodies (Figure 6d), their final displacement efficiency is averaged as 10.3\%, which is far less than the other two types. Meanwhile, the water broke through the front easily in the three models in which the averaged time of the water-free oil production is merely 0.21 PV. At 1.5 PV, the water cut had reached $100 \%$ in them, though about $1 \mathrm{~mL}$ of oil was still driven out between $1.5 \mathrm{PV}$ and 2.5 PV in Model 11\#.

Figure 7 is an example exhibiting the process of water flooding and the formation of the remaining oil in three sorts of reservoir bodies with Models 1\#, 7\#, and 12\#. 

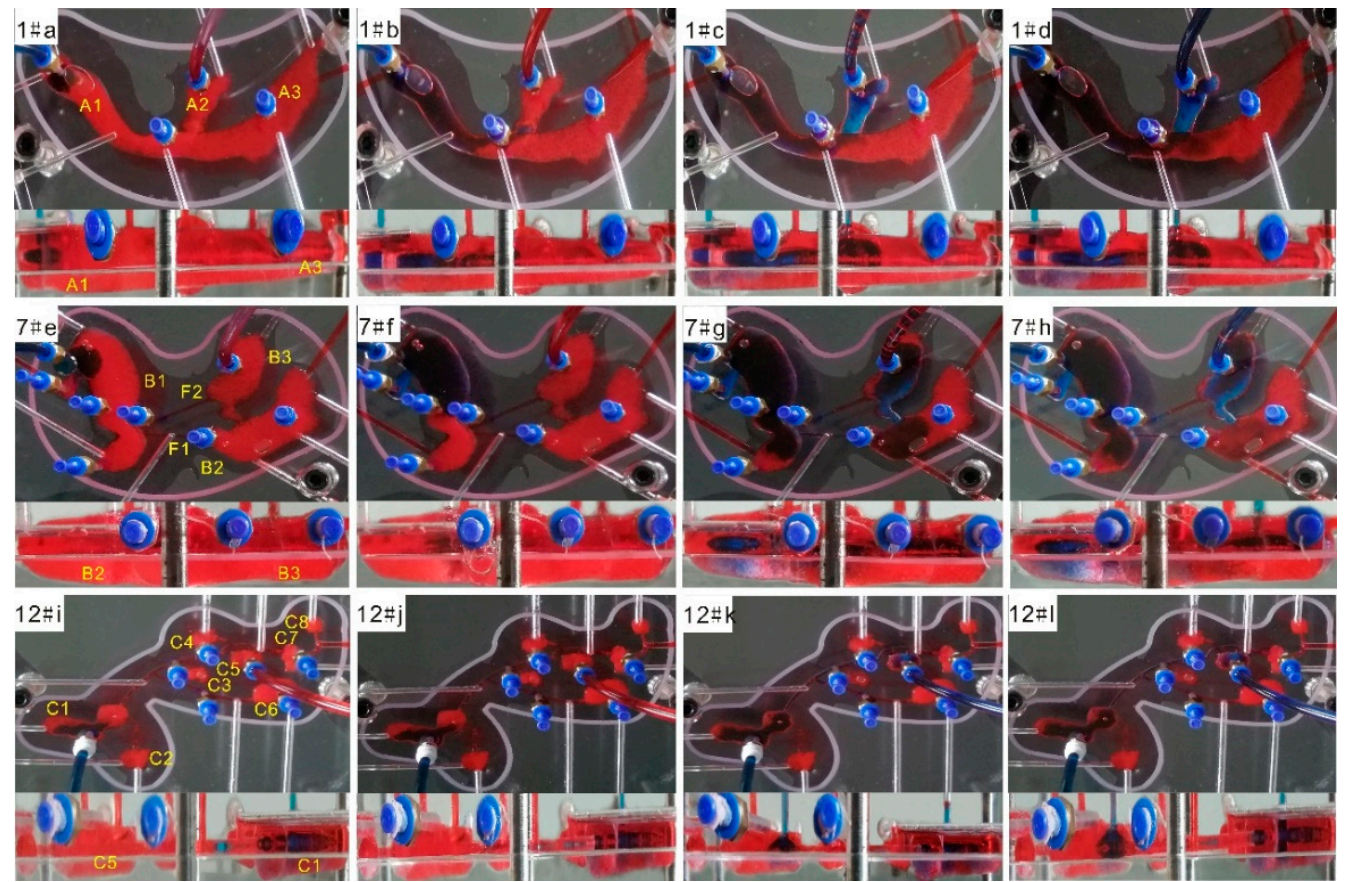

Figure 7. The processes of water flooding in Models $1 \#(\mathbf{a}-\mathbf{d}), 7 \#(\mathbf{e}-\mathbf{h})$ and 12\# (i-1).

At the initial stage, depending on the gravity differentiation, the water gathered on the upper surface of the filled areas in the caves (Figure 7a,e,i). Since the flow resistance in fillings is bigger than in unfilled areas, the water flowed predominantly along with the boundaries between two areas in cave A1, B1, and C1. Meanwhile, the water also immersed the fillings slowly.

Then, the oil/water interface moved horizontally towards the outlets (Figure $7 \mathrm{~b}, \mathrm{f}, \mathrm{j})$. However, the means of the connectivity caused the different processes of water drive in three models. In Model 1\# (Figure 7a), cave A1, A2, and A3 connect to each other by the dissolved caves. Thus, the oil/water interface moved towards cave A2 rapidly (Figure $7 \mathrm{~b}, \mathrm{c}$ ). Because cave A3 was away from the exit, the oil/water interface was not pushed to it. This lead to the residual oil (Figure 7c,d). In Model 7\# (Figure 7e), the fractures (F1 and F2) and the dissolved cave link cave B1, B2, and B3. In Model 12\# (Figure 7i), the fractures connect cave $\mathrm{C} 1$ to $\mathrm{C} 7$. The oil/water interfaces in cave $\mathrm{B} 1$ and $\mathrm{C} 1$ did go up vertically until they came to the locations of fractures (Figure $7 \mathrm{f}, \mathrm{j}$ ). The oil above both oil/water interfaces resided in them. After overcoming the additional force caused by the wettability in the fracture and flowing through fractures, the water entered cave B2 and C5 (Figure 7g,k). In the meantime, the main flow channel was transferred from F1 to F2, causing the discontinuous effect of the water drive on the oil in cave B2, though the water continuously was pushed into cave B2 (Figure 7g). Hence, there existed abundant residual oil in cave B2 (Figure 7h). During this stage, much oil was also replaced in the fillings of three models.

Afterward, the oil/water interface arrived in cave A2, B3, and C5. The elevating oil/water interface made the oil above them displaced. The period of water-free oil production ended up with their oil/water interfaces rising to the locations of outlets, and the water started to be seen in the outlets (Figure $7 \mathrm{c}, \mathrm{g}, \mathrm{k}$ ). The oil in the fillings was displaced during this period. The remaining oil belonged to the attic oil in cave $\mathrm{B} 3$ and $\mathrm{C} 5$.

Finally, the water occupied the dominant flow path, so the exits only produced pure water in cave A2, B3, and C5 (Figure 7d,h,l). During this period, due to the deviation from the main flow channel, the oil could not be washed out in cave C2, C3, C4, C6, C7, and C8 (Figure 7l). Nevertheless, much oil was also observed in the fillings of the caves affected by water.

Because the sizes of caves in Models 2\# and 7\# are larger than in Model 12\#, it was clearer to watch the rising oil/water interfaces in them. Hence, the gravity differentiation was utilized much 
better in them. Meanwhile, since the fractures connected small caves in Model 12\#, the main flow path was easier to form and further caused invalid water displacement for some caves in it. Thus, combined with water displacement efficiency and water breakthrough time, the intermediate and large scale reservoir bodies should be preferentially arranged with wells to exploit.

\subsubsection{Injection/Production Relationships}

\section{Wells Designed on Fractures or Intermediate-Sized Vugs}

For the averaged water displacement efficiency (Figure 8a), FIIVO of 36.22\% is higher than FOIVI of $25.64 \%$. The water breakthrough time of FIIVO is 0.17 PV longer than FOIVI (Figure 8b). Meanwhile, the residual oil area of FIIVO is less than FOIVI in Models 4\# and 7\# (Figure 9). Hence, placing the water well on the fracture and setting the oil well in the intermediate cave can gain a better effect of water flooding.
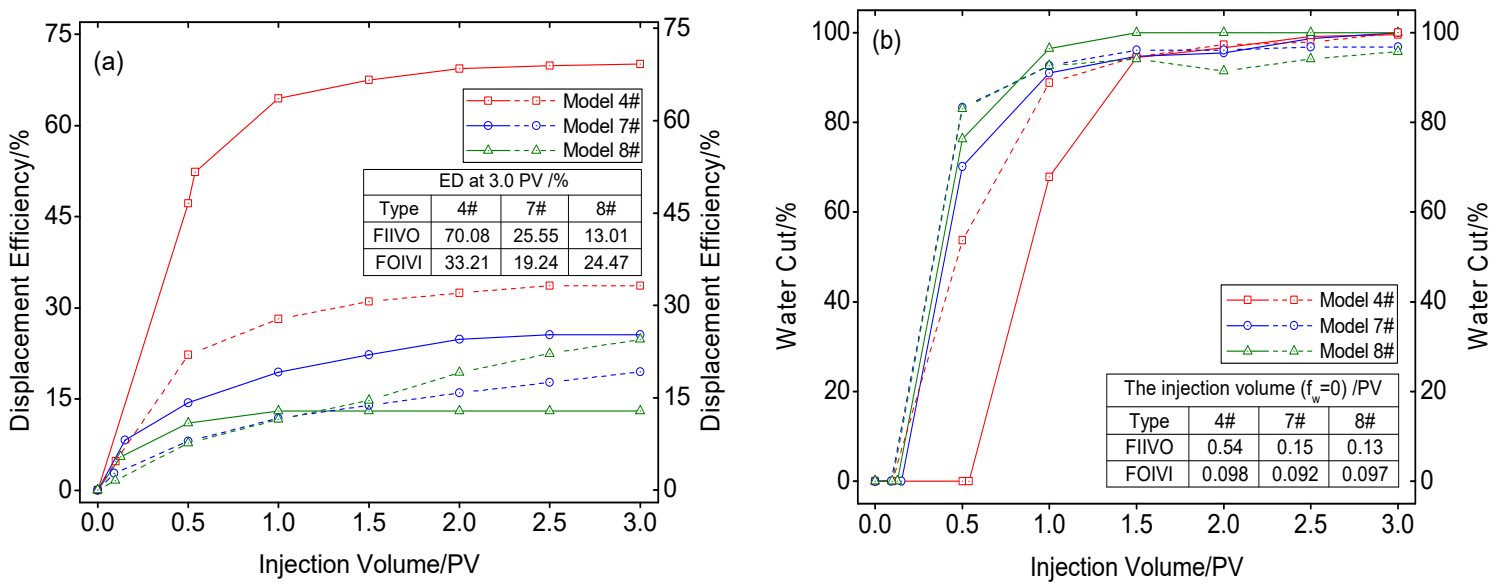

Figure 8. The curves of displacement efficiency (a) and the water cut (b) for Models 4\#, 7\#, and 8\#. The solid and dash lines are FIIVO and FOIVI, respectively.
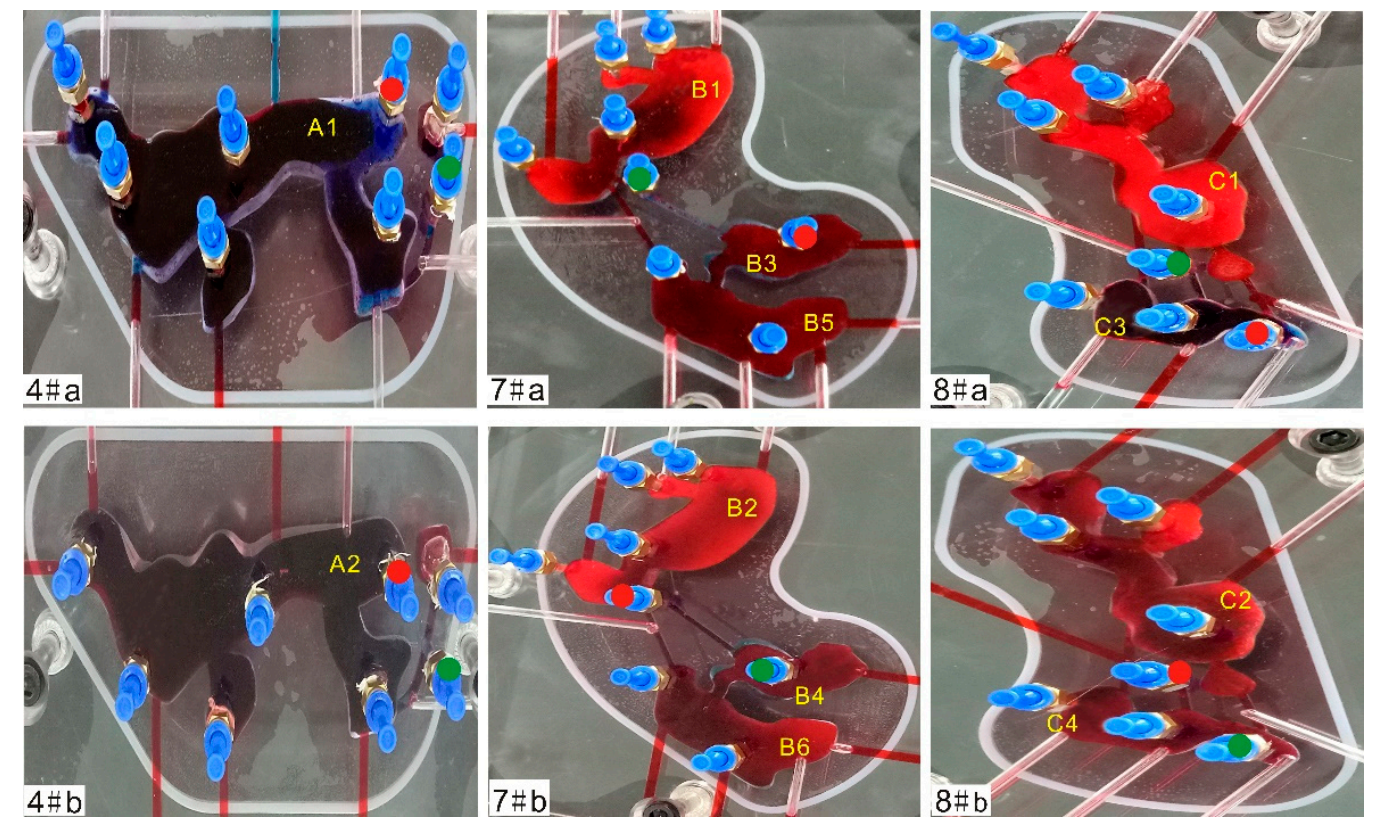

Figure 9. The comparisons between (a) FIIVO and (b) FOIVI in the residual oil distributions of Models $4 \#, 7 \#$, and $8 \#$. 
However, both the water displacement efficiency (Figure 8a) and the residual oil distributions (Figure 9) show that FOIVI is better in Model 8\#. This phenomenon was due to different amounts of main flow channels. During water flooding, only one main flow channel (yellow circle) was observed in FIIVO (Figure 10a), while three main flow channels (yellow circles) appeared in FOIVI (Figure 10b). In FIIVO, only cave C3 was affected by water drive (Figure 10a). However, in FOIVI, both cave C2 and C4 were swept by water (Figure 10b). So compared with FIIVO, FOIVI had the bigger sweep area of water flooding (Figure 9). Nevertheless, in Models 4\# and 7\# (Figure 9), the main flow channel was unique and constant in water flooding. So, the comparison of two relationships in Model 8\# may be insignificant for seeking laws of well placements design.

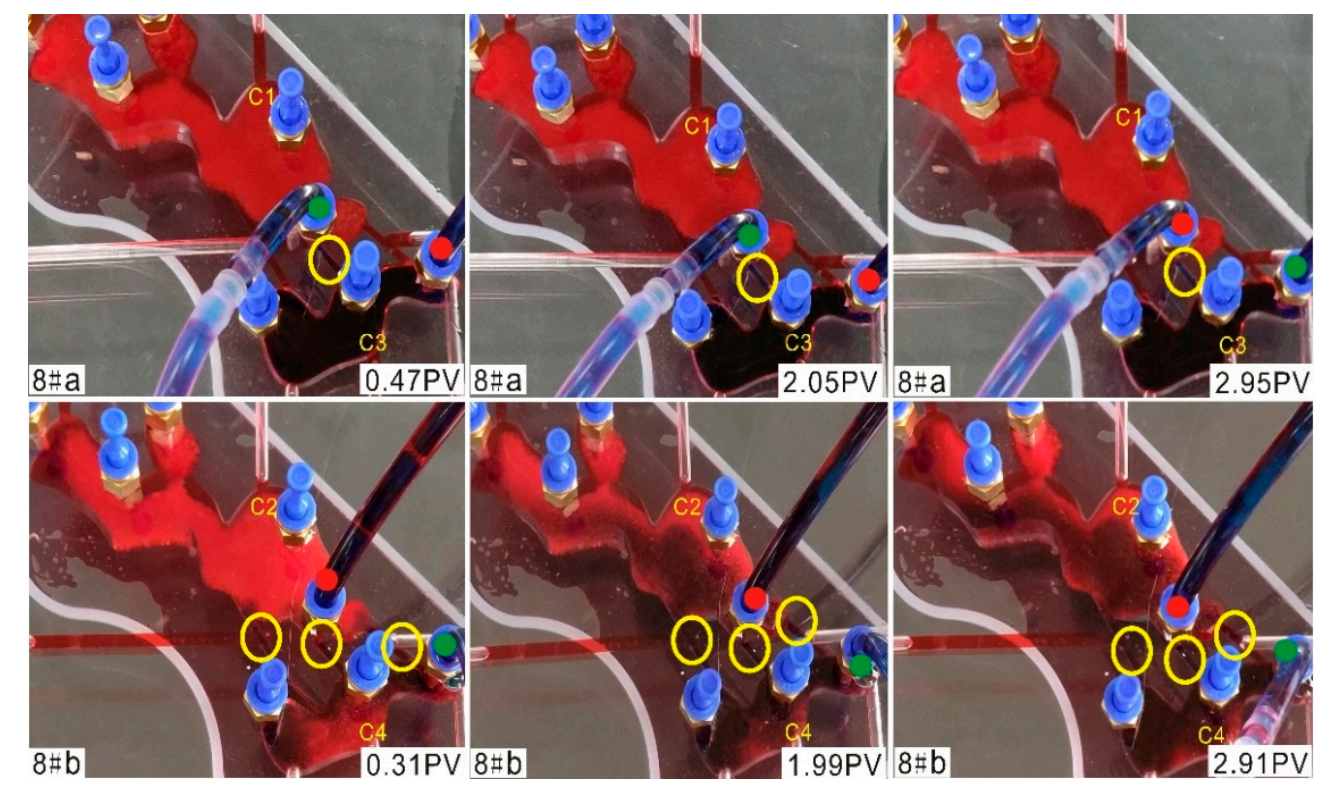

Figure 10. The flow channels in Model 8\# under (a) FIIVO and (b) FOIVI.

Wells Designed on Fractures or Small-Sized Vugs

In order to study the well placements on fractures and caves further, the small scale caves and the fractures were also combined to form FISVO and FOSVT.

In three models, the comparisons in the displacement efficiency indicate that FISVO was superior to FOSVT (Figure 11a). Moreover, the averaged injection volume of the former also exceeded the latter at the difference of $0.09 \mathrm{PV}$ during the period of water-free oil production (Figure 11b). The small sizes of the caves were attributed to this small difference. In addition, after water flooding, the remaining oil in cave A1, B1, and C1 was less than cave A2, B2, and C2 (Figure 12). Thus, FISVO would benefit the effect of water flooding.

Because of the low flow resistance, some caves apart from the main flow channel also were affected by water drive, such as cave A3, B3, B5, B7, C3, and C5 in Models 10\#a, 11\#a, and 12\#a (Figure 12). However, the same caves marked with A4, B4, B6, C4, and C6 were almost not driven by water. Meanwhile, the oil in some caves also was not displaced completely in FISVO and FOSVT, though these caves were connected with the main flow channel. 

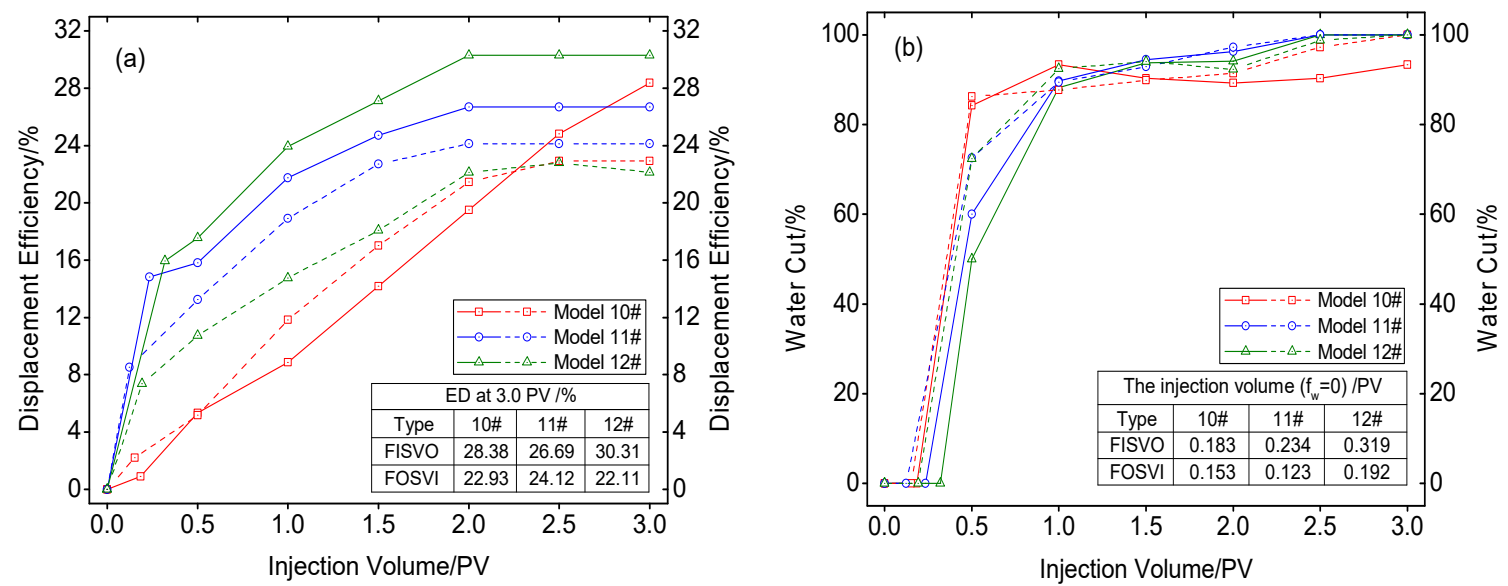

Figure 11. The curves of the displacement efficiency (a) and the water cut (b) for Models 10\#-12\#. The solid and dash lines represent FISVO and FOSVT, respectively.
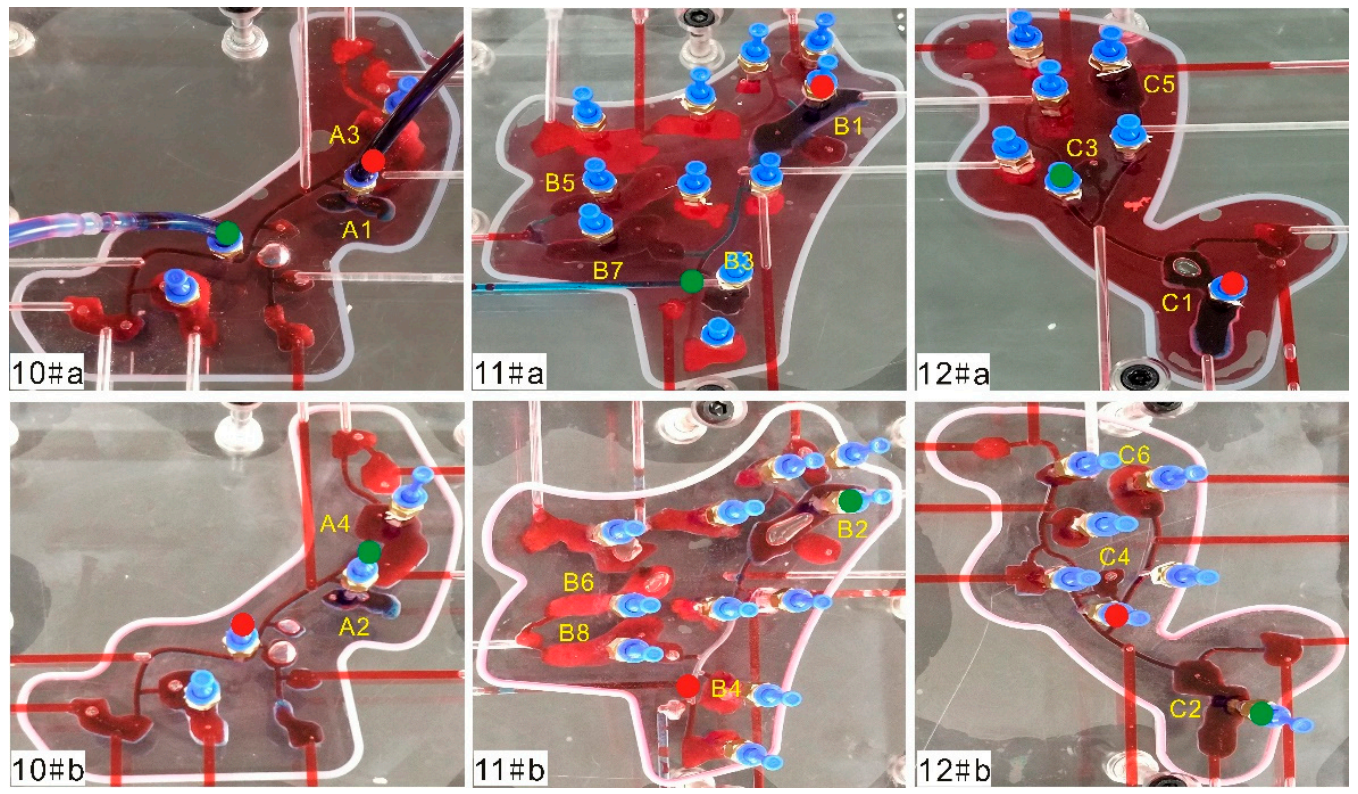

Figure 12. The comparisons between (a) FISVO and (b) FOSVI in the residual oil distributions of Models 10\#-12\#.

Wells Designed on Various-Scaled Vugs

The wells can also be placed on various scale caves. The averaged water displacement efficiency of SVIIIV at 3.0 PV was 24.85\% higher than this of SVOLIVI in Models 2\#, 4\#, and 9\# (Figure 13a). In SVIIIV and SVOLIVI, the averaged injection volume is $0.47 \mathrm{PV}$ and $0.16 \mathrm{PV}$, respectively (Figure 13b), both of which indicate the exit was easier to undergo water logging in the SVOLIVI. In addition, the residual oil in cave A3, B1, and C1 was less than in cave A4, B2, and C2 (Figure 14). Hence, the water flooding performance would be better, as the entrance was placed in the smaller caves, and the exit was arranged in the larger caves.

Meanwhile, since the structures of the caves were complex in Models 2\# and 9\#, cave A1, A2, C5, and C6 were approximately not flooded under SVIIIV and SVOLIVI (Figure 14). 

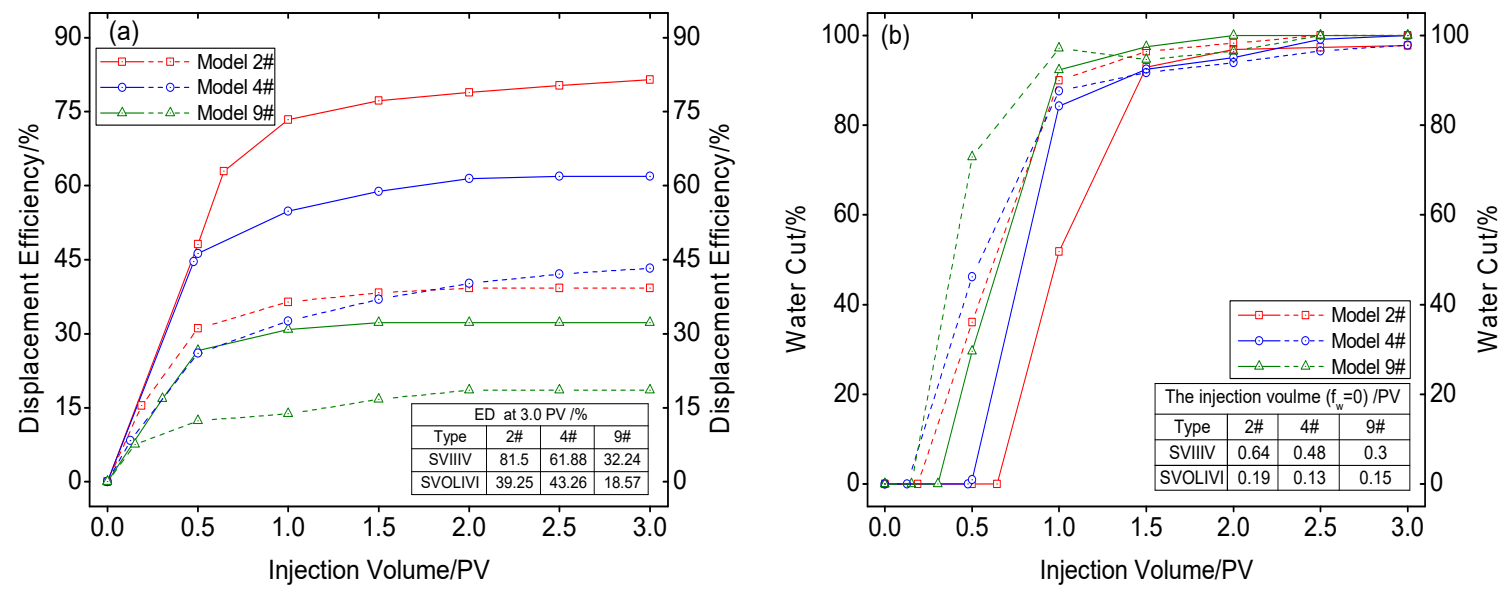

Figure 13. The curves of the displacement efficiency (a) and the water cut (b) for Models 2\#, 4\#, and 9\#. The solid and dash lines represent SVIIIV and SVOLIVI, respectively.
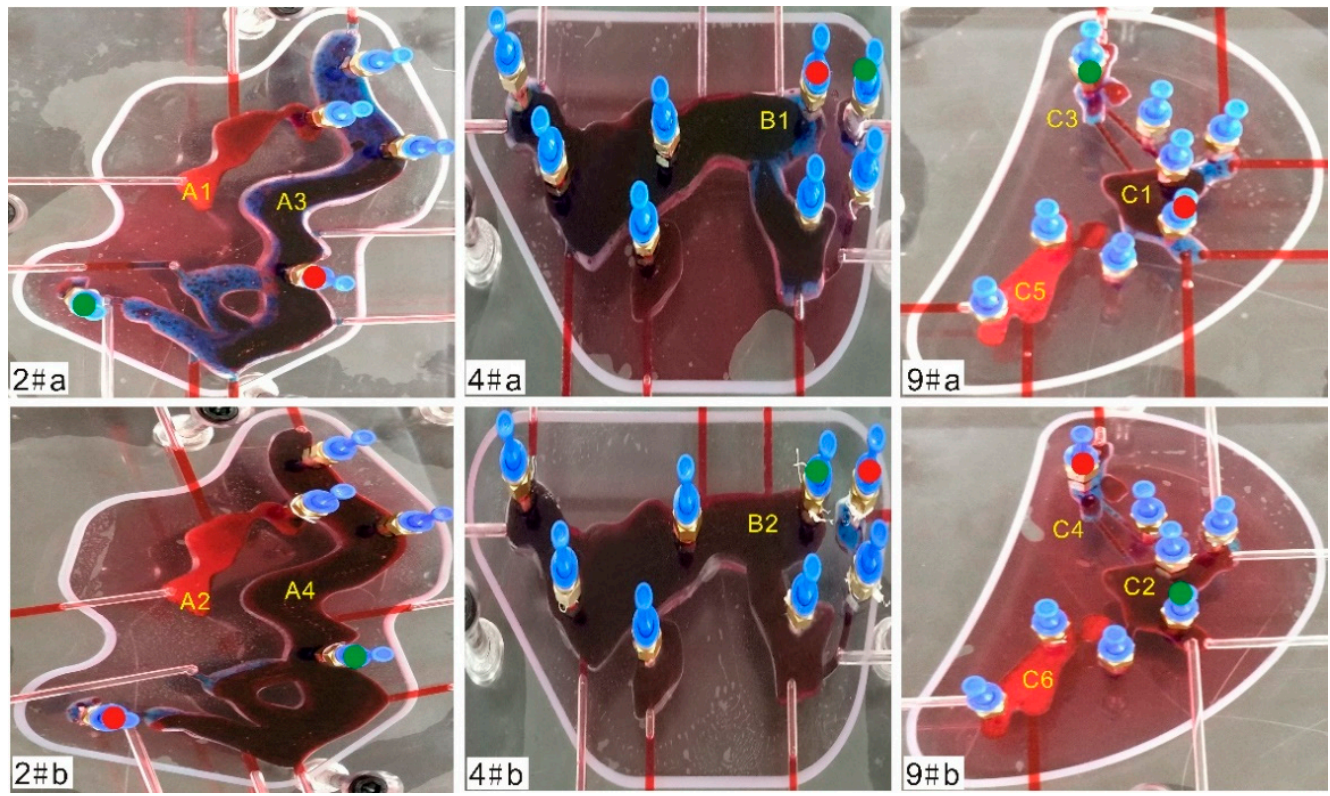

Figure 14. The comparisons between (a) SVIIIV and (b) SVOLIVI in the residual oil distributions of Models 2\#, 4\#, and 9\#.

Analysis of Injection/Production Relationships

In fact, six injection/production relationships represent six injection and production patterns in fractured-vuggy carbonate reservoirs. Various fractured-cave structures have exhibited different water flooding behaviors under these well placements. However, the gravity differentiation between oil and water was considered as the mechanism governing these behaviors. As shown in Figures 15 and 16, the dynamic processes in Model 4\# (Figure 9) and in Model 2\# (Figure 14) were analyzed to reveal this mechanism. The injection/production relationship in Model 4\# is both placing the injection well in the fracture while placing the production well in the intermediate scale cave (FIIVO) and placing the injection well in the intermediate scale cave while placing the production well in the fracture (FOIVI). The injection/production relationship in Model 2\# is both placing the injection well in the small scale cave while placing the production well in the intermediate scale cave (SVIIIV) and placing the injection well in the intermediate scale cave while the production well in the small scale cave (SVOLIVI). 

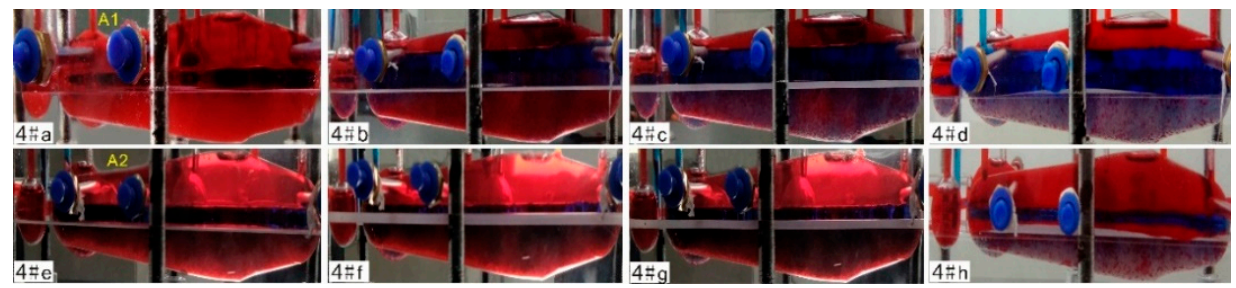

Figure 15. The oil/water interface changes in Model 4\# under (a-d) FIIVO and (e-h) FOIVI.
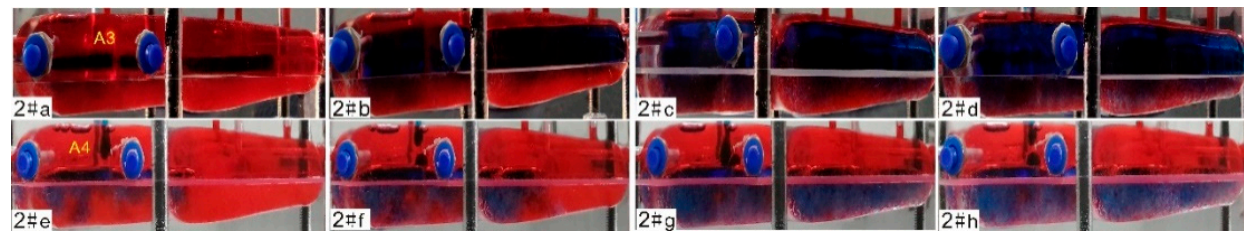

Figure 16. The oil/water interface changes in Model 2\# under (a-d) SVIIIV and (e-h) SVOLIVI.

Before the water entered the fracture, the water occupied the small cave quickly in SVIIIV. In FIIVO and SVIIIV, the drive force further pushed water to balance the additional force caused by wettability in the fracture. After water entering cave A1 (Figure 15a) and cave A3 (Figure 16a), the oil/water interface was advanced horizontally at first. Then, the water was accumulated on the upper of fillings because of the gravity differentiation. The oil/water interface was elevated vertically in cave A1 (Figure 15b) and in cave A3 (Figure 16b). The water gradually displaced the oil in the area without fillings. Meanwhile, water also partly immersed the fillings, but the oil was displaced a little in the fillings (Figures 15b and 16b).

After the oil/water interface arrived at the outlets, the water was observed at once in the exits. The oil/water interface almost remained constant in the following process (Figure 15c,d and Figure 16c,d). The oil could not be displaced above the oil/water interface again and remained in the cave. Furthermore, because of the gravity differentiation, the water also got over the capillary force in the pores of the fillings featured with the water wettability and further expelled the oil in the fillings (Figure 15c,d and Figure 16c,d). Finally, as the oil was driven out enough from the fillings, the water cut reached $100 \%$ in the exits (Figures $15 \mathrm{~d}$ and $16 \mathrm{~d}$ ). Nevertheless, some oil still remained in the fillings.

FOIVI and SVOLIVI behaved with different characteristics in two models. Since the fractures were carved on the horizontal plane, the raising oil/water interface in the vertical direction was almost not observed in cave A2 (Figure 15h) and in cave A4 (Figure 16h), and its corresponding height was lower than that in cave A1 (Figure 15d) and cave A2 separately (Figure 16d). The oil was not displaced above the oil/water interface. Meanwhile, as a drive, the gravitational force immersed the water much earlier in the fillings (Figures $15 \mathrm{f}$ and 16f). So, the oil was gradually driven out from the fillings (Figures 15g and $16 \mathrm{~g}$ ). However, there was still abundant residual oil in cave A2 and A4 (Figures 15h and 16h).

In these two injection/production relationships, the heights of entrances and exits are 0.5 and $36 \mathrm{~mm}$ in Model 4\# while 7 and $42 \mathrm{~mm}$ in Model 2\#, respectively. In FIIVO and SVIIIV, the heights of the entrances ( 0.5 and $7 \mathrm{~mm}$ ) were lower than those of the exits ( 36 and $42 \mathrm{~mm}$ ). Under the gravity differentiation, two relationships elevated the oil/water interfaces in intermediate or large caves, so a better water flooding effect was achieved. In FOIVI and SVOLIVI, the heights of the entrances (36 and $42 \mathrm{~mm}$ ) were higher than those of the exits $(0.5$ and $7 \mathrm{~mm})$. These relationships hindered the gravity differentiation from upraising oil/water interfaces. Hence, FOIVI and SVOLIVI are not proposed in well placement design.

In essence, the gravity differentiation must be used adequately for a reasonable injection/production relationship in fractured-vuggy carbonate reservoirs. 


\subsubsection{High/Low Positions of the Reservoir Body}

A reservoir body features with high and low parts in the spatial distributions. For a reservoir body, there were four injection and production patterns, including placing the injection well in the high part while placing the production well in the high part (HIHO), placing the injection well in the low part while placing the production well in the high part (LIHO), placing the injection well in the high part while placing the production well in the low part (HILO), and placing the injection well in low part while placing the production well in the low part (LILO). Their water flooding performances behaved differently in Model 2\#, 6\#, and 11\# (Figures 17 and 18).
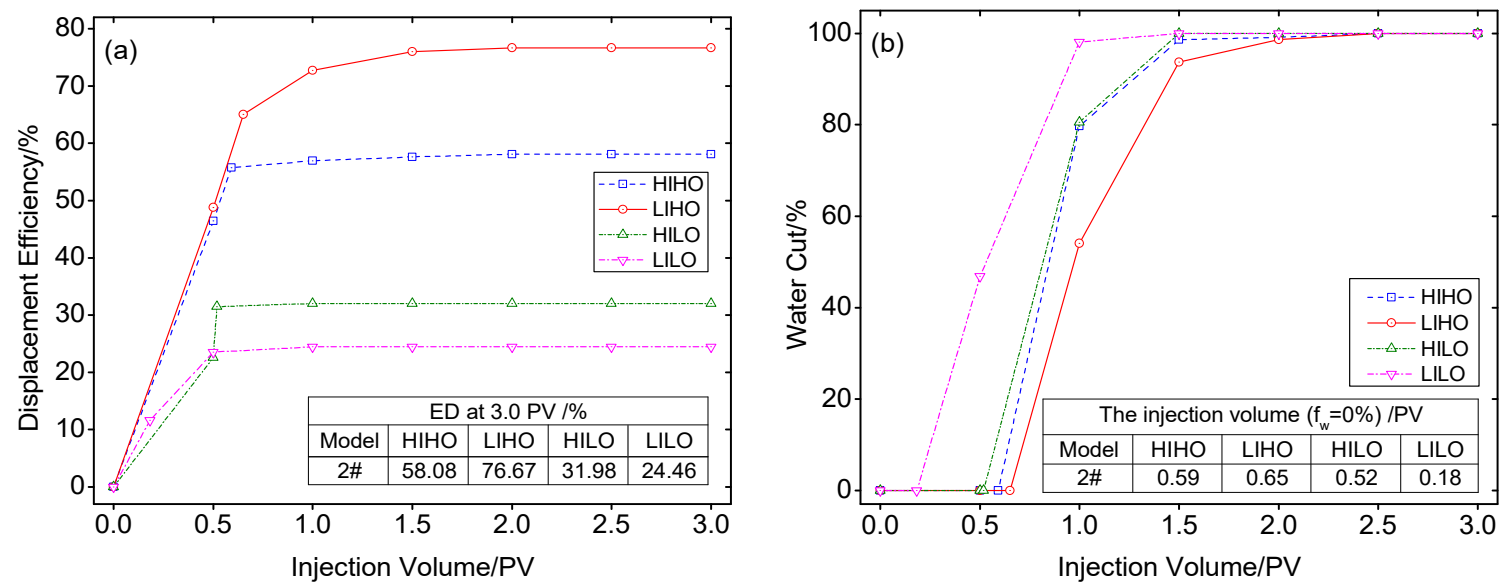

Figure 17. The curves of the displacement efficiency (a) and the water cut (b) for Model 2\# in HIHO, LIHO, HILO, and LILO.
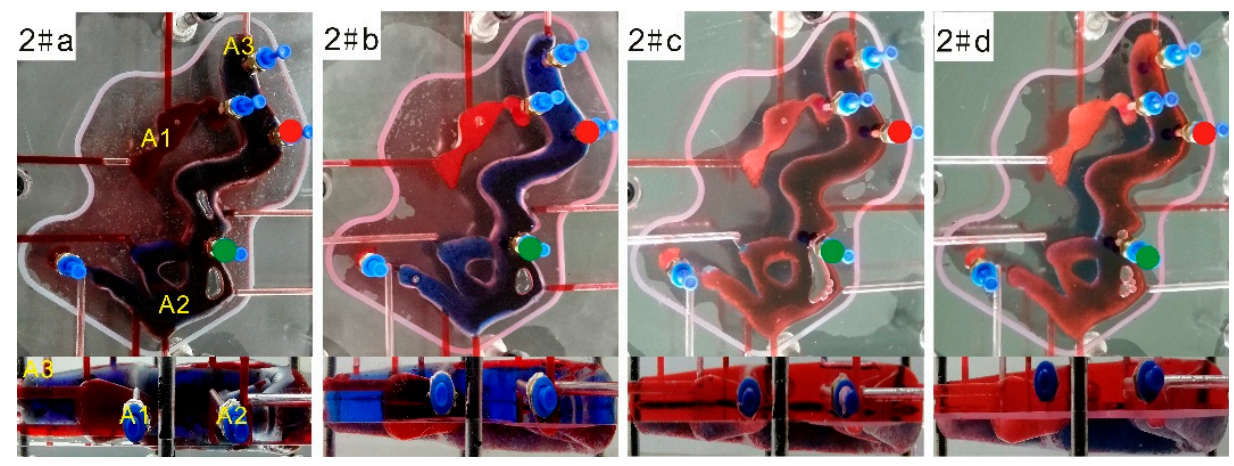

Figure 18. The comparisons in the residual oil distributions among HIHO (a), LIHO (b), HILO (c), and LILO (d) of Model 2\#, respectively.

\section{Large Scale Reservoir Body}

In Model 2\#, LIHO achieved the highest water displacement efficiency (Figure 17a) and the longest water-free oil production time (Figure 17b).

Under four injection and production patterns, a unique oil/water interface with different height was observed to exist in the whole reservoir body (Figure 18a-d). Since production wells were placed at the high part, the oil/water interfaces were also high in cave A2 and A3 (Figure 18a,b). At the same time, it was also observed that more oil in the fillings was displaced by LIHO instead of HIHO. Thus, LIHO was more advantageous to use gravitational differentiation. Due to using the low part to arrange the production well in HILO and LILO, their oil/water interfaces are apparently lower than those in LIHO and HIHO (Figure 18c,d). Because locating the injection well in the high position (Figure 18c) could sweep the oil a little in the unfilled zone of cave A2 and A3, the oil/water interface in the HILO 
(Figure 18c) was slightly higher than LILO (Figure 18d). However, under HILO and LILO, the gravity differentiation did not function well in the area without fillings, with much residual oil remaining.

In addition, the oil in cave A1 could hardly be driven out under four situations (Figure 18a-d), due to the complex vuggy structure and the deviation of the main flow channel.

Intermediate Scale Reservoir Body

In Model 6\#, cave B1 and B2 connect to each other by a fracture. In cave B1 and B2, the vertical height of two locations as the entrance or the exit is 42 and $44 \mathrm{~mm}$, respectively. Figure 19a,b indicates that LIHO still had the best water flooding performance like in Model 2\#.
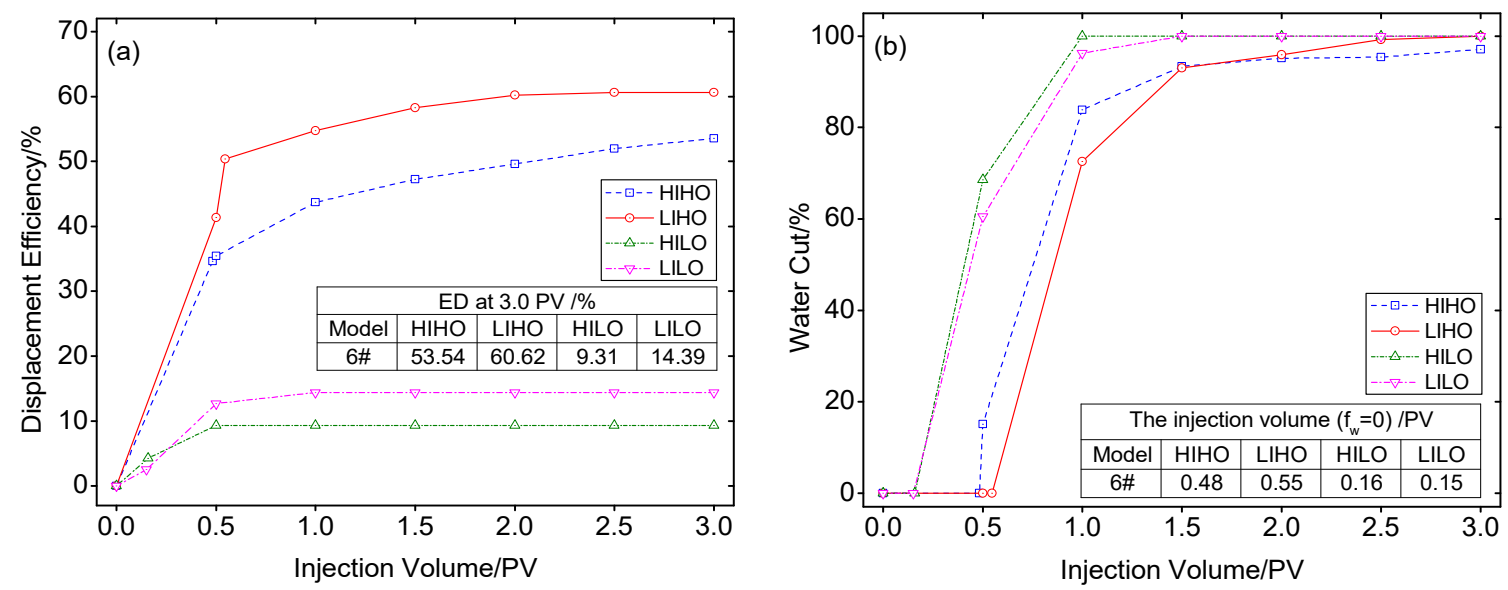

Figure 19. The curves of the displacement efficiency (a) and the water cut (b) for Model 6\# in HIHO, LIHO, HILO, and LILO.
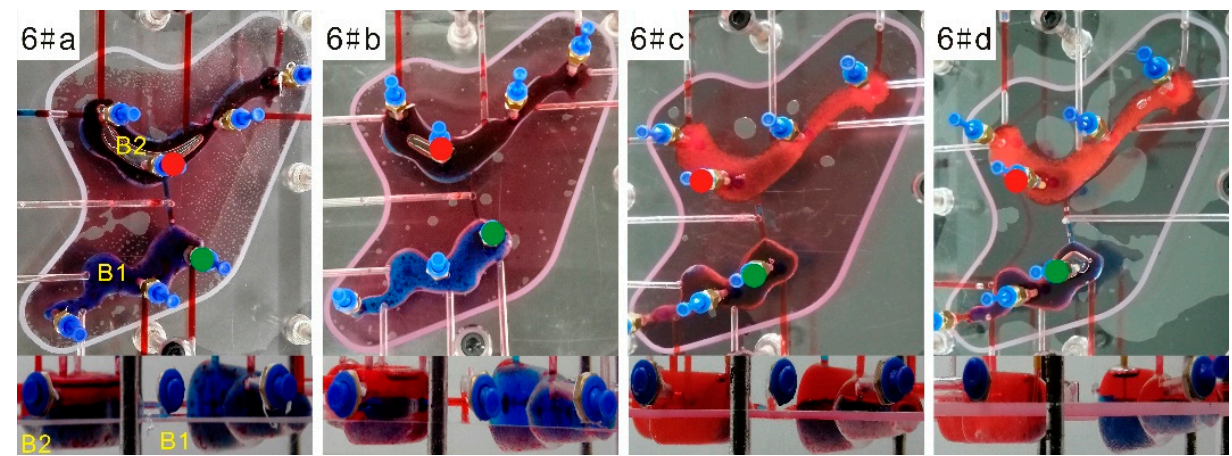

Figure 20. The comparisons in the residual oil distributions among HIHO (a), LIHO (b), HILO (c), and LILO (d) of Model 6\#, respectively.

Nevertheless, several different characteristics were still found in this case.

Firstly, the oil/water interface in cave B1 is higher than in cave B2 (Figure 20a-d). In other words, there did not exist a unique oil/water interface in the whole model. These oil/water interfaces were not only governed by the locations of the entrance and the exit but the orientations of fractures.

Secondly, arranging the production well in the high position lifted the oil/water interface in cave B1 and B2 (Figure 20a,b). Thus, using LIHO almost did not retain the oil in cave B1 (Figure 20b).

Thirdly, since the production well was placed in the low position, the oil in the fillings of cave B2 was displaced (Figure 20c,d). In cave B1, despite almost the same oil/water interfaces in HILO and LILO, the water flowed mainly along with the upper of fillings and entered the fracture easily in HILO, so oil was partly trapped in the fillings (Figure 20c), causing the smallest displacement efficiency (Figure 19a). In LILO, the oil in the fillings was mainly displaced (Figure 20d). 
Therefore, the use of the gravity differentiation was still vital to achieve better performances of water flooding in intermediate scale reservoir bodies.

\section{Small Scale Reservoir Body}

Compared with Models 2\# and 6\#, the sizes of the caves scaled down apparently in Model 11\#. Using cave $\mathrm{C} 1$ and $\mathrm{C} 6$ was to arrange the injection well and production well. The height of their locations is merely 12 and $10 \mathrm{~mm}$ separately. The fracture does connect cave C1 to C6. LIHO still possessed the highest water flooding efficiency (Figure 21a), but HILO had the longest water breakthrough time (Figure 21b).
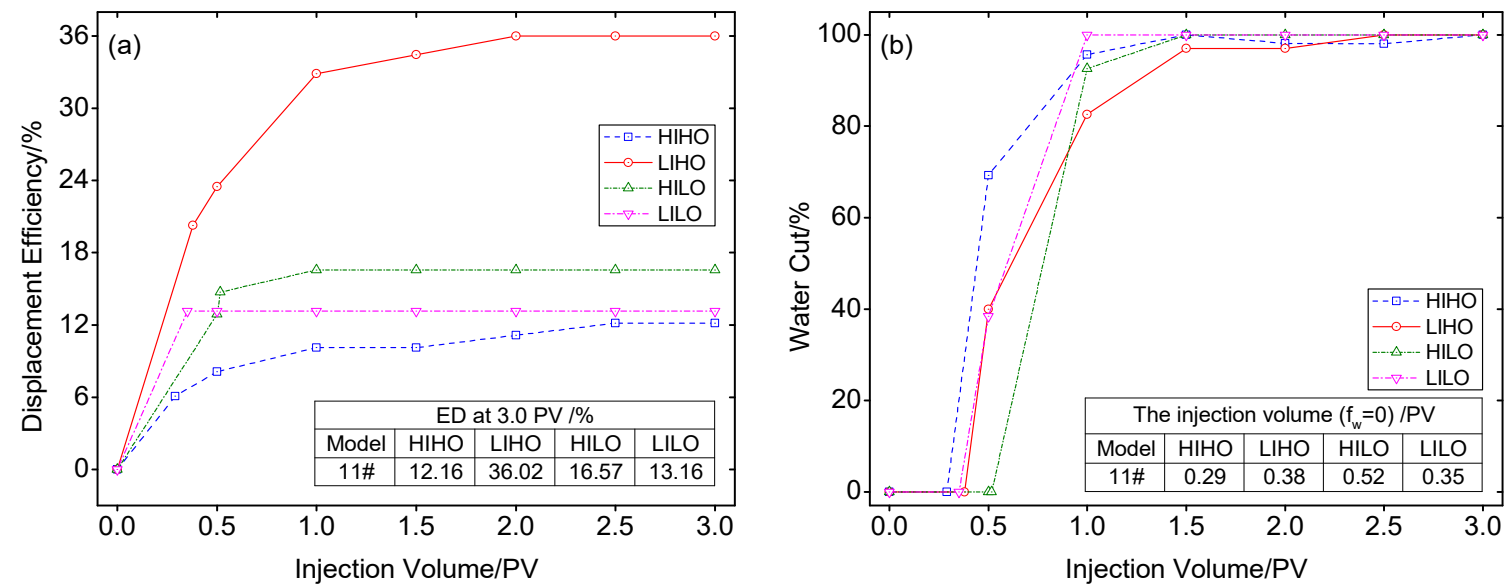

Figure 21. The curves of the displacement efficiency (a) and the water cut (b) for Model 11\# in HIHO, LIHO, HILO, and LILO.

In cave $\mathrm{C} 1$, placing the injection well in the low position used the gravity differentiation fully, so the remaining oil was not approximately observed (Figure 22b,d). Because placing the entrance in a high position made the water enter the fractures quickly, much of the oil was locked in the fillings (Figure 22a,c).
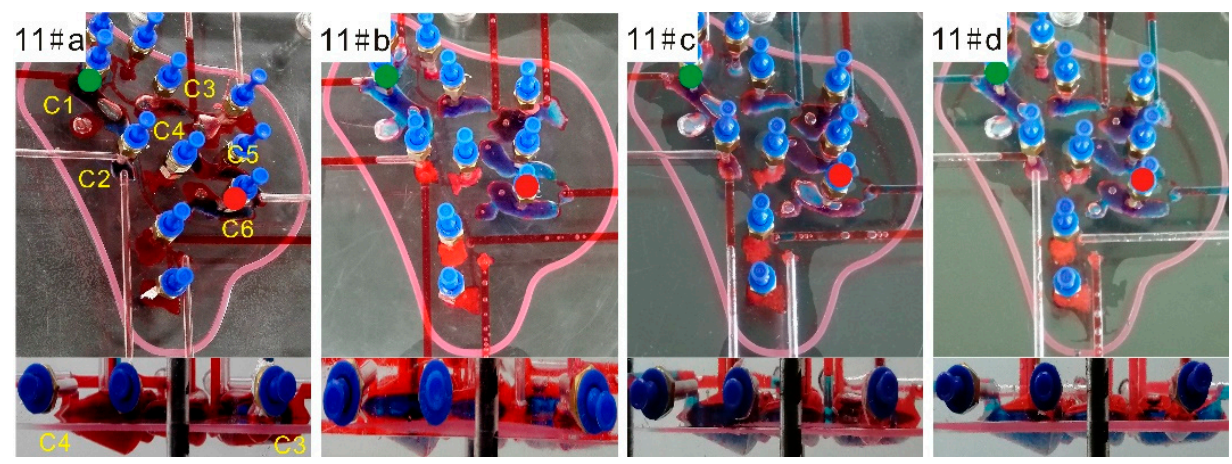

Figure 22. The comparisons in the residual oil distributions among HIHO (a), LIHO (b), HILO (c), and LILO (d) of Model 11\#, respectively.

In cave $\mathrm{C} 6$, the locations of the exits appeared unrelated to the remaining oil distributions. Although the exits of both HIHO and LIHO were placed in high positions, the remaining oil in HIHO was less than in LIHO (Figure 22a,b). This similar circumstance also occurred in HILO and LILO (Figure 22c,d). Various residual oil distributions in four situations indicate that the gravity differentiation was not the main factor to displace oil in cave C6.

Meanwhile, from cave $\mathrm{C} 2$ to $\mathrm{C} 5$ (Figure 22a-d), the residual oil was distributed irregularly in every cave. The residual oil of HIHO was most in cave C3 and C4 (Figure 22a). 
In addition, in cave $\mathrm{C} 1$ to $\mathrm{C} 6$, the small sizes of these caves caused the tough observation of their changing oil/water interfaces, though there was still gravity differentiation in them.

For a small scale reservoir body, the effect of water flooding was not only controlled by the gravity differentiation but fillings, fluid properties, flow channels, and fractured-cave structures. Given the water displacement efficiency (Figure 21a) and water breakthrough time (Figure 21b), LIHO may benefit the water drive to sweep these caves connected with the main flow channel. However, unlike the use of gravity differentiation to improve the effect of water flooding in Models 2\# and 6\#, sweeping more small caves was assumed as a possible mechanism controlling the water flooding effect in Model 11\#. Hence, a high/low position was not considered as a key factor of well placement design in this kind of reservoir body.

\subsection{Adjusting Injection and Production Pattern}

As shown in Table 4, the effect of the measures on not changing locations or amounts of wells (Schemes 1 and 2) was far inferior to that of the measures of changing locations or amounts of wells (Schemes 3-6). In Schemes 1 and 2, the locations and amounts of wells had not been adjusted. In Figure 23a, an example is combined of Models (7)(3) in Scheme 1. The main flow channel had not been altered during water flooding. Nonetheless, a certain effect was still achieved by this measure. The reason is that massive oil was observed to remain in the model, including the injection well (Figure 24), so oil close to the dominant flow path was partly flushed out as the old injection well was used as the production well. In Figure 23b, there was not any effect in the combined Models (7)(11) in Scheme 2, and water injection had not changed flow direction. Thus, only adding amounts of connected channels for flow was not supposed to enlarge the sweeping area of water flooding. In Schemes 3-6, some changes may occur in the main flow channels due to changing locations and amounts of wells. For instance, closing the old production well ensured water to move towards the new one in Scheme 3 (Figure 25), so the directions of the main flow channels were altered to improve the water flooding effect. The above comparisons show that the alteration of the main flow channels benefited the improvement of the water flooding effect.

Table 4. The effect of water flooding under various adjusting schemes.

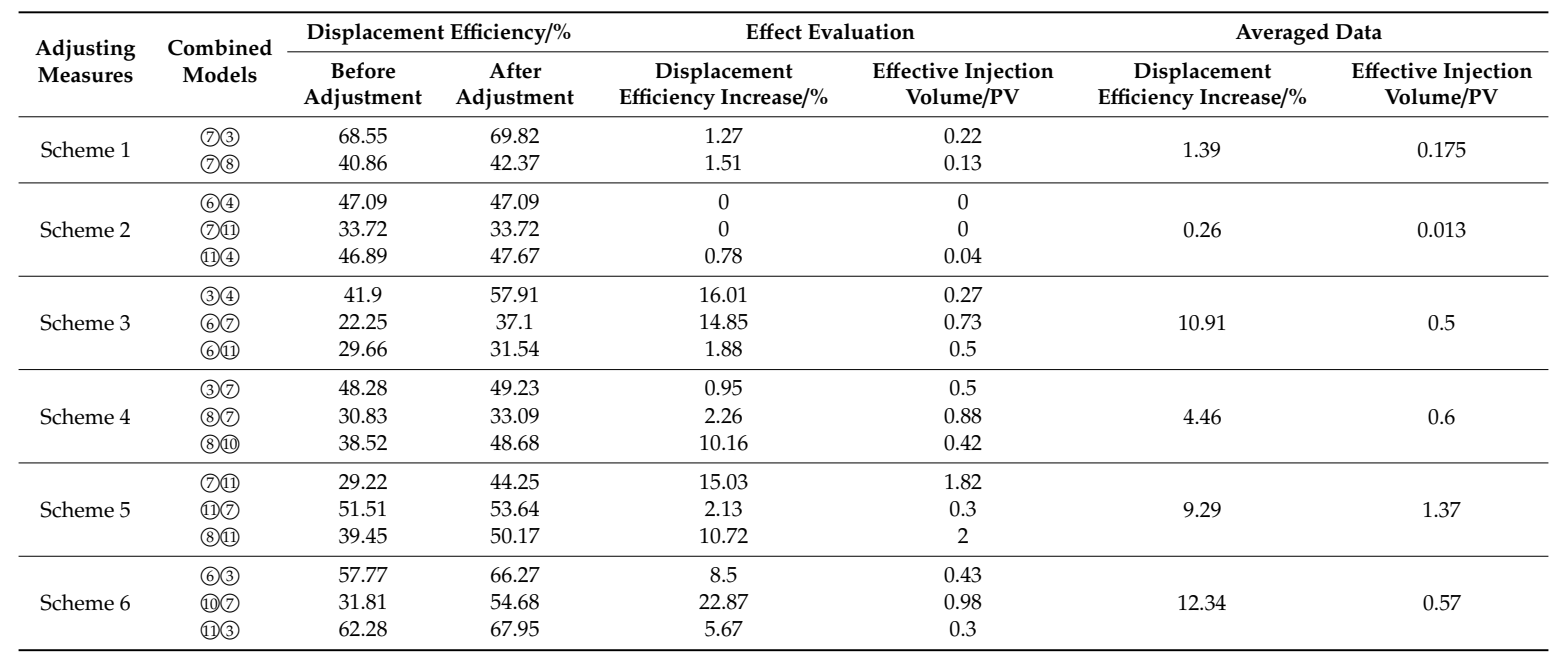

However, it does not mean that all measures on changing locations and amounts of wells must cause the change of the main flow channels, such as in Scheme 4 (Figure 26). After adjustment, the new production well named $\mathrm{Z}$ had produced nothing during water flooding in combined Models (3)(7), and the main flow channel was the same as that before 3.0 PV. In combined Models (8)(7, the new production well called S74 stopped production after a simulated oil bulk of $6 \mathrm{~mL}$ having been driven out. Meanwhile, the main flow pathway recovered like that at 3.0 PV. By contrast, in combined 
Models (8)10, the old production well TK659 had no production, and the new production well marked as A started to produce continuously, so the new main flow pathway was formed. The effect of water drive also did behave much better, as shown in Table 4. This further implies that the adjusting effect of water flooding was determined by whether new flow channels could be formed.

Moreover, the adjusting effect of water flooding also depended on the sizes and residual oil distributions of caves selected to arrange new wells. Take Scheme 6 as an example (Figure 27). At 3.0 PV, a lot of non-displaced oil remained in combined Models (6)(3) and (10)(7) separately, while great attic oil was distributed in combined Models (11)(3) (Figure 27). At the same time, the sizes of the caves in the new production well TK617 and Z are larger than those in the new production well marked as C (Figure 27). Although the altered flow channels were observed in three combined models, both displacement efficiency increases and the effective injection volume of combined Models (11)(3) were lower than those in the other two combinations. Hence, new formed flow channels should pass through relative large-sized caves containing enough residual oil. This identical mechanism also appeared in combined Models (6)(11) of Scheme 3 and combined Models (11)(7) of Scheme 5.

In addition, the injection and production pattern was "one injection and two productions" in Scheme 4 and was "two injections and one production" in Schemes 5 and 6, separately. As shown in Table 4, from the view of averaged data, the effect of using Schemes 5 and 6 is superior to that of using Scheme 4. Hence, "two injections and one production" was better to favor the enhanced effect of water flooding in these experiments.

On the whole, forming new flow channels was supposed to control the effect of the injection and production pattern adjustment under water flooding. Both scales of cave chosen to arrange new wells and residual oil distribution also influenced the final adjusting effect. The effective measures included shutting down old production wells while adding new production wells (Scheme 3), adding new injection wells (Scheme 5), or switching production wells into injection wells while adding new production wells (Scheme 6).
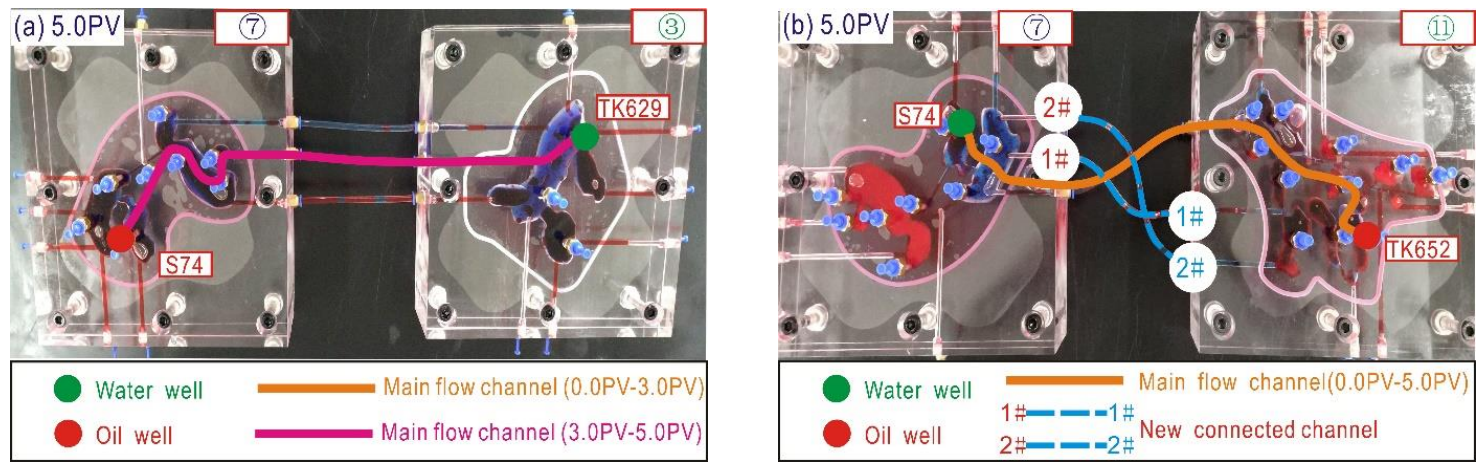

Figure 23. Changes of main flow channels in the combined Models (7)(3) (a) in Scheme 1 and (7)(11) in Scheme 2 (b).
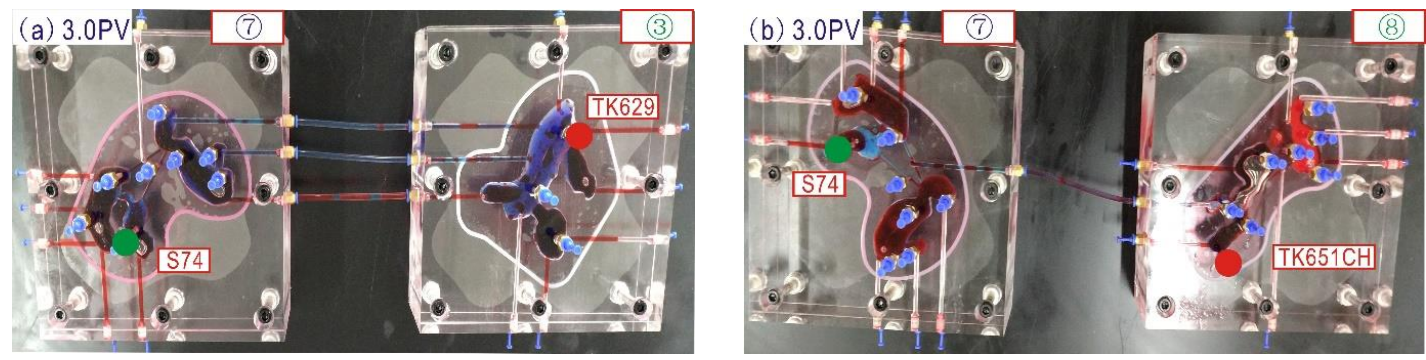

Figure 24. Residual oil distributions of the combined model (7)(3) (a) and (7)(8) (b) in Scheme 1 at 3.0 PV. 

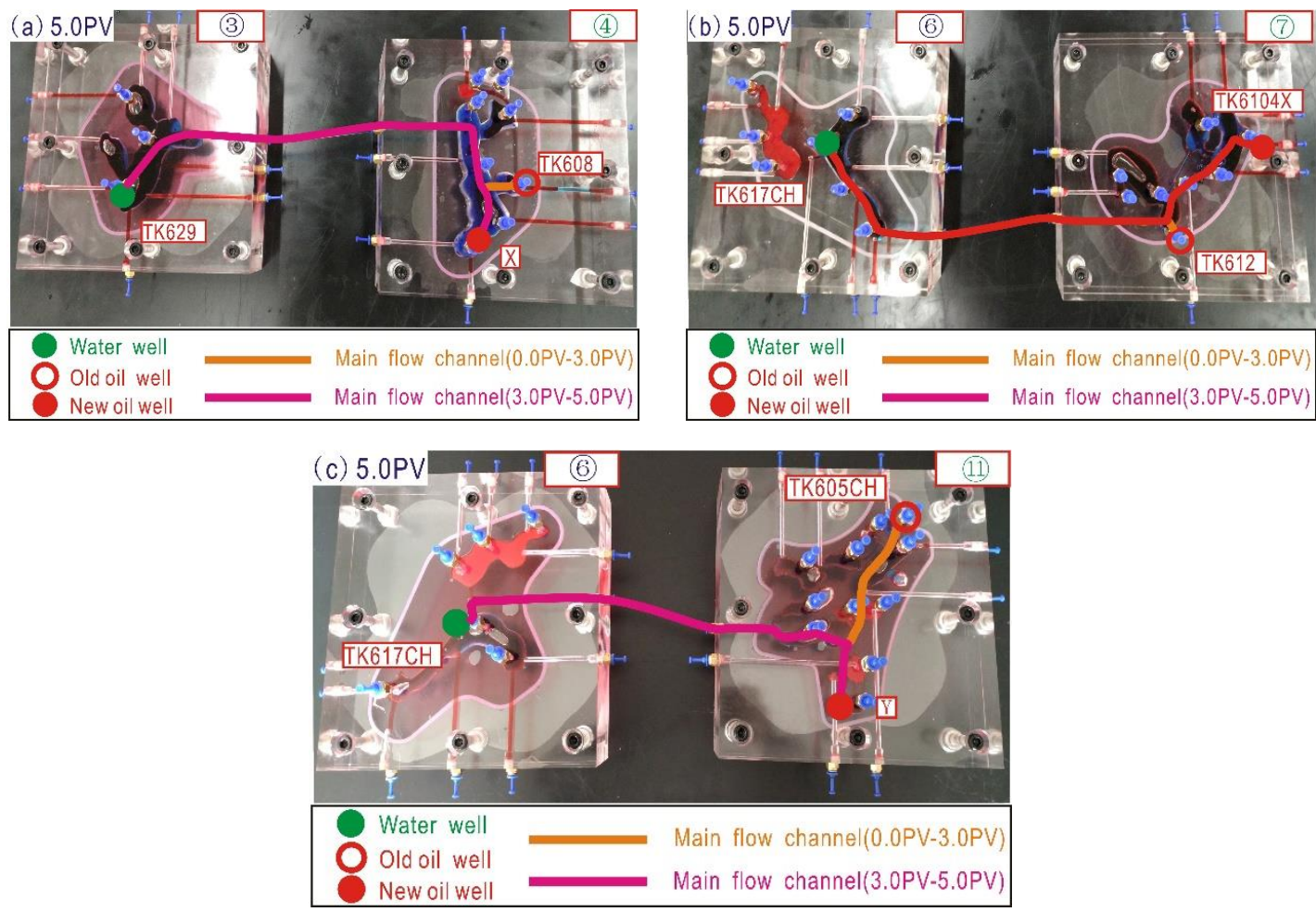

Figure 25. Main flow channel changes of the combined model (3)(4) (a), (6)(7) (b), and (6)(11) (c) in scheme 3 , respectively.
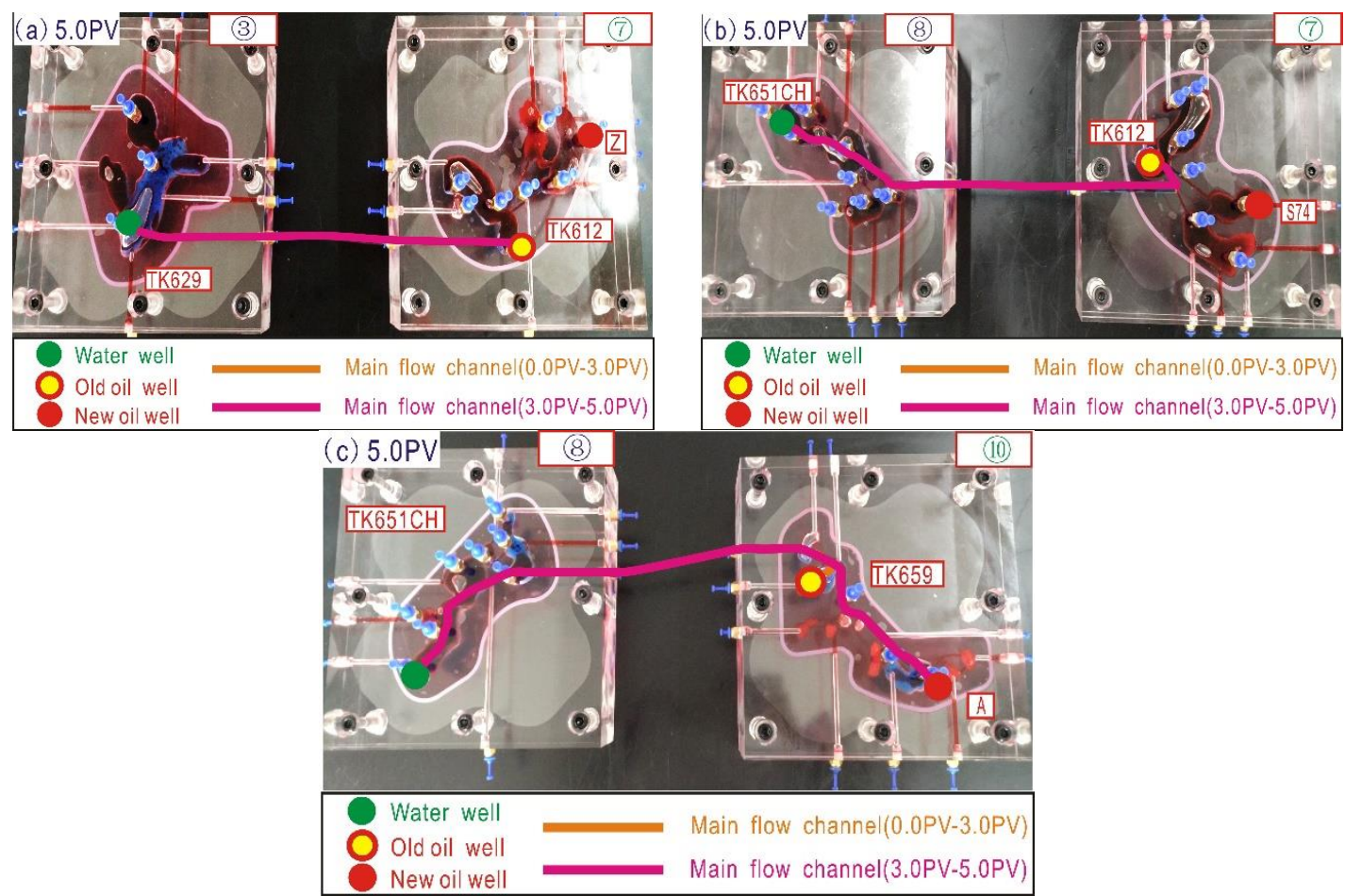

Figure 26. Main flow channel changes of the combined model (3)(7) (a), (8)(7) (b), and (8)(10) (c) in scheme 4 , respectively. 

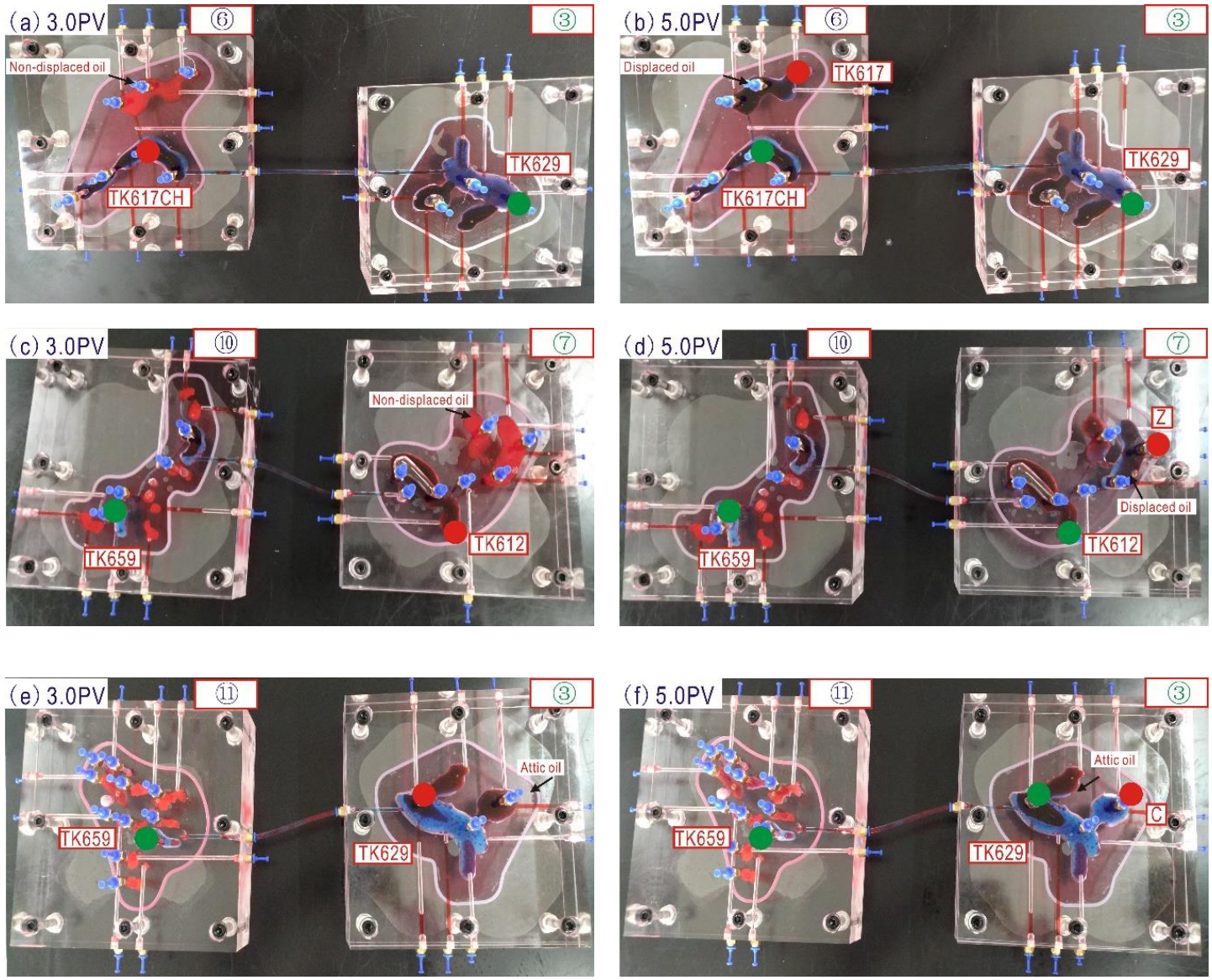

Figure 27. Residual oil distributions of the combined model (6)(3) (a vs. b), (10)(7)(c vs. d), and (11)(3) (e vs. f) in Scheme 6 at 3.0 PV and 5.0 PV, respectively.

For fractured-vuggy reservoirs, different emphases existed in constituting and adjusting injection and production patterns separately. The former was to make full use of gravitational differentiation between oil and water, while the latter was to ameliorate the water driving effect for the caves containing enough remaining oil through forming new flow channels. In fact, both of them surpassed their original contents. An example is the adjusting measure on opening the old oil well while opening the new oil well (Scheme 4). In spite of adjusting the injection and production pattern, a relatively inferior water flooding effect was achieved due to no formation of newly effective flow channels. This result implies that the validity of flow channels was crucial to improving the effect of water flooding. In our understanding, this validity of flow channels was embodied in two aspects that are to form new ones and to make these new ones work on intermediate or large scaled caves with enough residual oil. Nevertheless, in actual reservoirs, it is tough to meet these two aspects simultaneously by directly adjusting flow channels, particularly in letting new flow channels pass through caves with a large quantity of oil still remaining. According to experimental results, if caves with sufficient residual oil were arranged by adding a new injection well or production well and at the same time, the present flow channels were adjusted directly, the adjusting effect of water flooding may be controllable. In other words, the adjustment of both well location and flow channel were proposed to adjust together. Consequently, the contents of injection and production patterns were supposed to include flow channel adjustment.

On the other hand, although there are different main missions in constituting and adjusting injection and production patterns, their common objectives are to utilize gravitational differentiation well. Therefore, the measures on the former also play a significant role in the latter. For instance, in adjusting the injection and production pattern, apart from residual oil distribution, using gravitational 
differentiation reasonably also should be taken into consideration as appropriate caves are chosen to adjust. Physical simulation was employed to study our topic in the laboratory. Although we have combined this method partly with actual production characteristics in the Tahe oilfield [45], some specific methods had not yet been developed to put the experimental measures into practice. This awaits our further investigation.

\section{Conclusions}

Due to extremely strong heterogeneity, constituting and adjusting injection and production patterns in fractured-vuggy reservoirs differ from those in traditional reservoirs. This difference lies in how to use gravity segregation and how to form effective flow channels. Through the results of physical simulation in this work, the former can be achieved by selecting reservoir bodies with intermediate and large scales preferentially to exploit, or arranging injection well in fractures or small caves while placing production well in large caves, or putting injection/production wells in low/high parts of a reservoir body with intermediate and large scales separately. The latter can be solved by shutting down an old production well while adding new a production well, adding a new injection well, or switching a production well into an injection well while adding a new production well. Considering the complex connectivity in actual fractured-vuggy reservoirs, a suggestion is to adjust the injection and production pattern with the flow channel together.

Author Contributions: All the authors contributed to this paper. J.H., D.L., and R.T. conceived and designed the experiments; J.H., A.L., and S.W. performed the experiments and wrote the paper; J.H., Y.L. and X.L. prepared the experiments and analyzed the data. All authors have read and agreed to the published version of the manuscript.

Funding: This research was funded by the National Major Science and Technology Projects of China, grant number "2016ZX05053-002-003".

Acknowledgments: This research is supported by the National Major Science and Technology Projects of China (2016ZX05053-002-003).

Conflicts of Interest: The authors declare no conflicts of interest.

\section{References}

1. Li, Y.; Hou, J.; Li, Y. Features and hierarchical modeling of carbonate fracture-cavity reservoirs. Pet. Explor. Dev. 2016, 43, 600-606. [CrossRef]

2. Hu, X.; Li, Y.; Quan, L.; Kong, Q.; Wang, Y.; Lye, X. Three-dimensional geological modeling of factured-vuggy carbonate reservoirs: A case from the Ordovician reservoirs in Tahe-IV block, Tahe oilfield. Oil Gas Geol. 2013, 34, 387-393.

3. Tangen, G.I.; Smaaskijaer, G.; Bergseth, E.; Clark, A.; Fossli, B.; Claudey, E.; Qiang, Z. Experience from Drilling a Horizontal Well in a Naturally Fractured and Karstified Carbonate Reservoir in the Barents Sea Using a CML MPD System. In Proceedings of the IADC/SPE Managed Pressure Drilling and Underbalanced Operations Conference and Exhibition, Amsterdam, The Netherlands, 9-10 April 2019.

4. Liao, M.; Pei, Y.; Chen, P.; Liu, X.; He, J. Formation and controlling factors of karst fracture-cave reservoir in the 4th block of Tahe Oilfield. J. Southwest Pet. Univ. 2013, 35, 1-8.

5. Li, Y.; Fan, Z. Developmental pattern and distribution rule of the fracture-cavity system of Ordovician carbonate reservoirs in the Tahe Oilfield. Acta Petrolei Sin. 2011, 32, 101-106.

6. Li, Y. Ordovician carbonate fracture-cavity reservoirs identification and quantitative characterization in Tahe Oilfield. J. China Univ. Pet. 2012, 36, 1-7.

7. Li, Y.; Kang, Z.; Xue, Z.; Zheng, S. Theories and practices of carbonate reservoirs development in China. Pet. Explor. Dev. 2018, 45, 669-677. [CrossRef]

8. Wang, L.; Dou, Z.; Lin, T.; Zhao, H.; Luo, J. Study on the visual modeling of water flooding in carbonate fracture-cavity reservoir. J. Southwest Pet. Univ. 2011, 33, 121-124.

9. $\mathrm{Li}$ J.; Chen, Z.; Gao, S. Microcosmic experiment modeling on water-driven-oil mechanism in fractured-vuggy reservoirs. Pet. Geol. Exp. 2009, 31, 637-642. 
10. Cruz-Hernández, J.; Islas-Juárez, R.; Pérez-Rosales, C.; Rivas-Gómez, S.; Pineda-Muñoz, A.; González-Guevara, J.A. Oil Displacement by Water in Vuggy Fractured Porous Media. In Proceedings of the SPE Latin American and Caribbean Petroleum Engineering Conference, Buenos Aires, Argentina, 25-28 March 2001.

11. Li, S.; Li, Y. An experimental research on water injection to replace the oil in isolated caves in fracture-cavity carbonate rock oilfield. J. Southwest Pet. Univ. 2010, 32, 117-120.

12. Li, A.; Zhang, D.; Yao, J.; Gao, C.; Lyu, A. Physical simulation of water flooding in fractured-vuggy unit. J. China Univ. Pet. 2012, 36, 130-135.

13. Zheng, Z.; Zhu, T.; Hou, J.; Luo, M.; Gao, Y.; Wu, X.; Qu, M. Visible research on remaining oil after nitrogen flooding in fractured-cavity carbonate reservoir. Pet. Geol. Recover. Effic. 2016, 23, 93-97.

14. Zheng, X.; Sun, L.; Wang, L.; Yi, M.; Yang, D.; Dong, G. Large-scale visible water/oil displacing physical modeling experiment and mechanism research of fracture-vuggy reservoir. Geol. Sci. Technol. Inf. 2010, $29,77-81$.

15. Zhao, Q.; Zhang, J.; Ding, B.; Wang, Y. Physical simulation of gas enhanced oil recovery for fractured-vuggy carbonate reservoirs in Tahe Oilfield. Sci. Technol. Eng. 2017, 17, 55-62.

16. Yuan, D.; Hou, J.; Song, Z.; Wang, Y.; Luo, M.; Zheng, Z. Residual oil distribution characteristic of fractured-cavity carbonate reservoir after water flooding and enhanced oil recovery by $\mathrm{N} 2$ flooding of fractured-cavity carbonate reservoir. J. Pet. Sci. Eng. 2015, 129, 15-22. [CrossRef]

17. Yuan, D.; Hou, J.; Song, Z.; Luo, M.; Zheng, Z.; Qu, M. Optimization of water injection methods and N2 flooding for EOR in Tahe fractured-vuggy carbonate reservoir. J. Northeast Pet. Univ. 2015, 39, 102-110.

18. Wang, J.; Liu, H.; Ning, Z.; Zhang, H.; Hong, C. Experiments on water flooding in fractured-vuggy cells in fractured-vuggy reservoirs. Pet. Explor. Dev. 2014, 41, 67-73. [CrossRef]

19. Qu, M.; Hou, J.; Qi, P.; Zhao, F.; Ma, S.; Churchwell, L.; Wang, Q.; Li, H.; Yang, T. Experimental study of fluid behaviors from water and nitrogen floods on a 3-D visual fractured-vuggy model. J. Pet. Sci. Eng. 2018, 166, 871-879. [CrossRef]

20. Lyu, X.; Liu, Z.; Hou, J.; Lyu, T. Mechanism and influencing factors of EOR by N 2 injection in fractured-vuggy carbonate reservoirs. J. Nat. Gas Sci. Eng. 2017, 40, 226-235. [CrossRef]

21. Ji, X.; Pu, W.; Jin, F.; Zhang, J.; Zhao, S.; Zhao, Q. Physical simulation experiment research on enhancing "attic oil" recovery in fracture-cavity reservoir. Fault Block Oil Gas Field 2016, 23, 375-379.

22. Guo, P.; Yuan, H.; Li, X.; Ma, H. Experiments on gas injection mechanisms in carbonate fracture-cavity reservoir using microvisual model. J. China Univ. Pet. 2012, 36, 89-93.

23. Zhang, D. Study of Production Mechanism for Fractured-Vuggy Carbonate Reservoirs. Ph.D. Thesis, China University of Petroleum, Beijing, China, 2012.

24. Wang, J.; Liu, H.; Zhang, J.; Zhao, W.; Huang, Y.; Kang, Z.; Zheng, S. Experiments on the influences of well pattern on water flooding characteristics of dissolution vug-cave reservoir. Pet. Explor. Dev. 2018, 45, 1035-1042. [CrossRef]

25. Li, X.; Rong, Y. Optimization research on reasonable injection-production pattern in Tahe Oilfield fractured carbonate reservoir. Drill. Prod. Technol. 2013,36, 47-52.

26. Lu, X.; Rong, Y.; Li, X.; Wu, F. Construction of injection-production well pattern in fractured-vuggy carbonate reservoir and its development significance: A case study from Tahe oilfield in Tarim Basin. Oil Gas Geol. 2017, 38, 658-664.

27. Li, Y. The theory and method for development of carbonate fractured-cavity reservoirs in Tahe oilfield. Acta Pet. Sin. 2013, 34, 115-121.

28. Peter, P.; Bi, L.; Yalchin, E.; Richard, E.E.; Qin, G.; Li, J.; Ren, Y. Multiphysics and Multiscale Methods for Modeling Fluid Flow Through Naturally Fractured Vuggy Carbonate Reservoirs. In Proceedings of the SPE Annual Technical Conference and Exhibition, Anaheim, CA, USA, 11-14 November 2007.

29. Nwachukwu, A.; Jeong, H.; Pyrcz, M.; Lake, L.W. Fast evaluation of well placements in heterogeneous reservoir models using machine learning. J. Pet. Sci. Eng. 2018, 163, 463-475. [CrossRef]

30. Nasrabadi, H.; Morales, A.; Zhu, D. Well placement optimization: A survey with special focus on application for gas/gas-condensate reservoirs. J. Nat. Gas Sci. Eng. 2012, 5, 6-16. [CrossRef]

31. Liu, C.; Wei, X.; Xu, S.; Fu, Z. The overview of geophysical techniques in prediction of carbonate rock reservoir. Progress Geophys. 2007, 22, 1815-1822.

32. Kang, S.; Datta-Gupta, A.; John Lee, W. Impact of natural fractures in drainage volume calculations and optimal well placement in tight gas reservoirs. J. Pet. Sci. Eng. 2013, 109, 206-216. [CrossRef] 
33. Hamida, Z.; Azizi, F.; Saad, G. An efficient geometry-based optimization approach for well placement in oil fields. J. Pet. Sci. Eng. 2017, 149, 383-392. [CrossRef]

34. Forouzanfar, F.; Reynolds, A.C.; Li, G. Optimization of the well locations and completions for vertical and horizontal wells using a derivative-free optimization algorithm. J. Pet. Sci. Eng. 2012, 86, 272-288. [CrossRef]

35. Cheng, Y.; McVay, D.A.; John Lee, W. A practical approach for optimization of infill well placement in tight gas reservoirs. J. Nat. Gas Sci. Eng. 2009, 1, 165-176. [CrossRef]

36. Bagherinezhad, A.; Boozarjomehry Bozorgmehry, R.; Pishvaie, M.R. Multi-criterion based well placement and control in the water-flooding of naturally fractured reservoir. J. Pet. Sci. Eng. 2017, 149, 675-685. [CrossRef]

37. Arinkoola, A.O.; Onuh, H.M.; Ogbe, D.O. Quantifying uncertainty in infill well placement using numerical simulation and experimental design: Case study. J. Pet. Explor. Prod. Technol. 2015, 6, 201-215. [CrossRef]

38. Ariadji, T.; Haryadi, F.; Rau, I.T.; Aziz, P.A.; Dasilfa, R. A novel tool for designing well placements by combination of modified genetic algorithm and artificial neural network. J. Pet. Sci. Eng. 2014, 122, 69-82. [CrossRef]

39. Wang, Z.; Wang, S.; Tang, W. Seismic response and frequency difference analysis of cavern-type reservoirs in carbonates in Tahe oilfield. Oil Gas Geol. 2004, 25, 93-98.

40. Wang, S.; Lu, X. Prediction techniques for deep carbonate reservoirs in Tahe Oilfield. Geophys. Prospect. Pet. 2004, 36, 153-158.

41. Wang, D.; Li, Y.; Hu, Y.; Li, B.; Deng, X.; Liu, Z. Integrated dynamic evaluation of depletion-drive performance in naturally fractured-vuggy carbonate reservoirs using DPSO-FCM clustering. Fuel 2016, 181, 996-1010. [CrossRef]

42. Rong, Y.; Pu, W.; Zhao, J.; Li, K.; Li, X.; Li, X. Experimental research of the tracer characteristic curves for fracture-cave structures in a carbonate oil and gas reservoir. J. Nat. Gas Sci. Eng. 2016, 31, 417-427. [CrossRef]

43. Ni, X.; Shen, A.; Pan, W.; Zhang, R.; Yu, H.; Dong, Y.; Zhu, Y.; Wang, C. Geological modeling of excellent fracture-vug carbonate reservoirs: A case study of the Ordovician in the northern slope of Tazhong palaeouplift and the southern area of Tabei slope, Tarim Basin, NW China. Pet. Explor. Dev. 2013, 40, 444-453. [CrossRef]

44. Liu, Y.; Rong, Y.; Yang, M. Detailed classification and evaluation of reserves in fracture-cavity units for carbonate fracture-cavity reservoirs. Pet. Geol. Exp. 2018, 40, 431-439.

45. Yang, B.; He, J.; Lyu, D.; Tang, H.; Zhang, J.; Li, X.; Zhao, J. Production optimization for water flooding in fractured-vuggy carbonate reservoir-From laboratory physical model to reservoir operation. J. Pet. Sci. Eng. 2020, 184, 106520. [CrossRef]

(C) 2020 by the authors. Licensee MDPI, Basel, Switzerland. This article is an open access article distributed under the terms and conditions of the Creative Commons Attribution (CC BY) license (http://creativecommons.org/licenses/by/4.0/). 